ELEVATING THE NEWS: HOW ENGAGEMENT EDITORS ASSESS SUCCESS IN THEIR COMMUNITY ENGAGEMENT EFFORTS

A Thesis
presented to
the Faculty of the Graduate School
at the University of Missouri-Columbia
In Partial Fulfillment
of the Requirements for the Degree
Master of Arts
KELLY MOFFITT
Dr. Amanda Hinnant, Thesis Supervisor
DECEMBER 2013


(C) Copyright Kelly Moffitt 2013 All Rights Reserved 
The undersigned, appointed by the dean of the Graduate School, have examined the thesis entitled

\section{ELEVATING THE NEWS: HOW ENGAGEMENT EDITORS ASSESS SUCCESS IN THEIR COMMUNITY ENGAGEMENT EFFORTS}

presented by Kelly Moffitt, a candidate for the degree of master of arts, and hereby certify that, in their opinion, it is worthy of acceptance.

Professor Amanda Hinnant

Professor Tim Vos

Professor Joy Mayer

Professor Lissa Behm-Morawitz 


\section{DEDICATION}

Thanks to my family and friends who continued to ask about this thesis even when I had no new or interesting updates to offer. Your love and support have meant the world to me. Thanks to my parents who have funded my education selflessly and allowed me time to learn more about my passion.

A special thanks to my dad, for simply sitting with me when I thought I could write no more and cheering me on when I thought none of the problems could be solved. 


\section{ACKNOWLEDGEMENTS}

A big thank you to all of my professors at the University of Missouri, without whom I would not have gotten to this point in my academic career and life. To Dr. Amanda Hinnant, thank you for taking a chance on this thesis and guiding me through the world of academia with your grace and insight. To Dr. Tim Vos and Dr. Lissa Behm-Morawitz, thank you for contributing your depth of knowledge about theory and your kind guidance to this thesis. And, finally, to Professor Joy Mayer, thank you most infinitely for introducing me to the world of community engagement in journalism all those years ago and supporting my need to find out more both academically and in the newsroom. 


\section{TABLE OF CONTENTS}

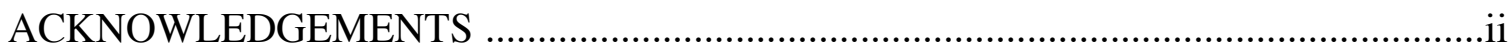

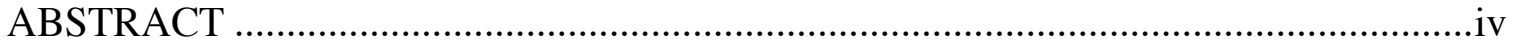

Chapter

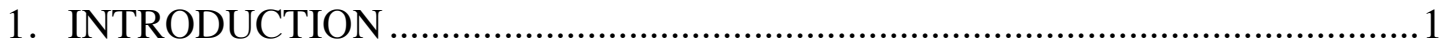

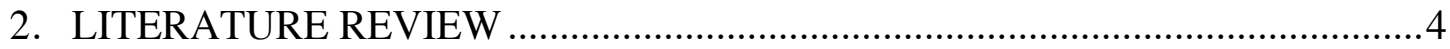

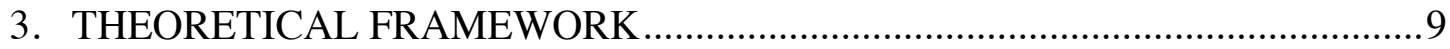

Public Journalism

Gatekeeping Theory

Bourdieu's Capital

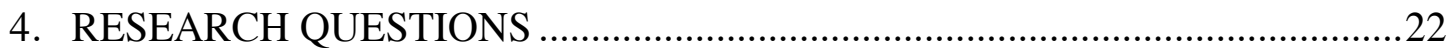

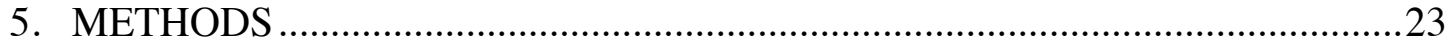

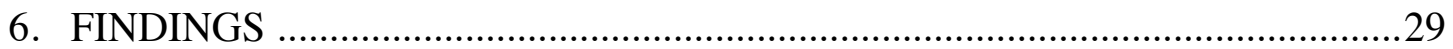

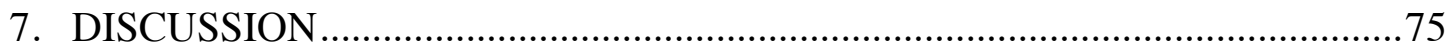

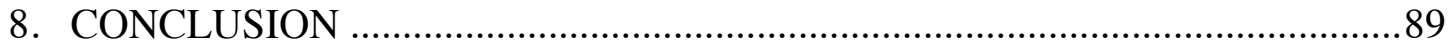

APPENDICES

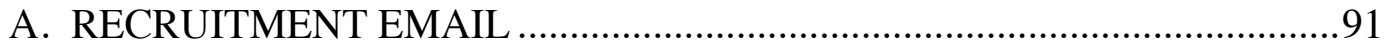

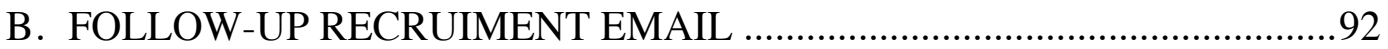

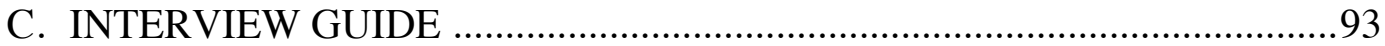

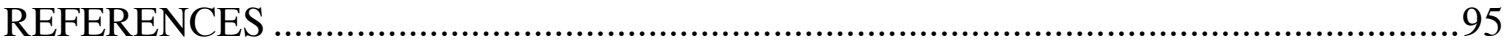




\title{
ELEVATING THE NEWS: HOW ENGAGEMENT EDITORS ASSESS SUCCESS IN THEIR COMMUNITY ENGAGEMENT EFFORTS
}

Kelly Moffitt

\author{
Dr. Amanda Hinnant, Thesis Supervisor
}

\begin{abstract}
Community engagement is a news industry buzzword that has recently seen professionalization in newsrooms in the form of a community engagement editor. Little research has been done on this type of editor and how they know what they're doing is working and this academic research seeks to fill that hole in journalistic knowledge. This study used 10 semi-structured interviews with engagement editors (or those who do similar work with a different title) to delve into what their position actually entails, how they measure and assess the success of their work and how that informs how they balance the journalistic and business value of their work. This study found three types of emphases in editors doing community engagement work and found seven types of barriers to assessment and measurement of success, though it did find that community engagement editors do measure a variety of things both qualitatively and quantitatively that impact their decision making. This study also found that community engagement journalists at online newspapers fall in line with traditional journalistic ideas of separation between editorial and business departments in newspapers, even if they are making strides in understanding how the two worlds interconnect.
\end{abstract}




\section{CHAPTER ONE: INTRODUCTION}

As one of the news industry's current "it" terms, community engagement holds the idealistic promise of how the relationship between the people and the press should be: a perfect balance of reader participation and interaction with the news content coupled with a transparent and responsive newsroom. Today, journalists say that community, or, audience engagement (involving the audience in the news) is a standard practice in the field of journalism (Mayer, 2011, p. 144). Editors at digital news organizations usually find engagement to be a good thing. Whether or not they practice it is a whole other issue. The rules of how to "do" engagement are not clear. Whether staffs are stretched thin or money is tight, the list of reasons for abstaining from practicing engagement goes on.

Audience engagement, however, to those who practice it is considered the lifeblood of the newsroom. As Kovach and Rosenstiel put it in The Elements of Journalism: "Engagement really falls under the journalist's commitment to the citizenry," (Kovach \& Rosenstiel, 2007, p. 189). In order for the practice of audience engagement to grow and spread to newsrooms across the country, a road map for creating good, successful engagement needs to be set out. Likewise, newsrooms need to know how to measure if they're accomplishing the goal of engaging their audience and if their work is economically viable. This study seeks to answer the questions of what an engagement editor is, what of their efforts are considered most successful in newsrooms employing them, how the editors in charge of those efforts measure and assess the success of those 
efforts, and what the implications of the new role of community engagement editor are in journalism.

This research utilized an in-depth, semi-structured interview method by interviewing those who are already doing engagement in their capacity as an engagement, outreach, social media, or community editor at online newspapers that have a print edition as well. In order to describe what engagement editors do, this research will first review research on public journalism and how that has translated into the term community engagement. Public journalism grew to prominence in the early ' 90 s as a movement that sought to reform how journalists work, emphasizing the involvement of citizens in the journalistic process and its discussion (Ahva, 2012, p. 126). The emergence of the community engagement editor position in online newspapers can be seen as a concrete, professional outgrowth of the public journalism movement as it is practiced today, though the position does vary from strict public journalism principles. To better understand how this relatively new type of editor makes decisions, this research employed a theoretical framework of gatekeeping, with an emphasis on the individual level of analysis. In a nutshell, gatekeeping theory in its application to journalism represents a logical process that journalists go through to make selection decisions about what news makes it into a news product that then makes its way to the audience (Shoemaker \& Vos, 2009). Finally, in order to understand the position of community engagement on both a cultural and economic level, the literature review will address Pierre Bourdieu's notions of capital and how that view has traditionally played out in the field of journalism. By utilizing these three ideas, this research will help to place these 
new editors within the historical spectrum of the decision-making role of the journalist and determine how, if at all, these editors operate differently.

Furthermore, this research is integral to understanding audience engagement efforts at newspapers today. It will set out what early adopters of audience engagement techniques do at the online newspapers where they work, what they have determined they are doing successfully, what they have determined does not work, how they determine that distinction, and how that plays into decision making on what community engagement techniques make it into news products and how the role of community engagement editor is justified in the newsroom. Hopefully, this research will provide the stepping-stones for newspapers newly adopting engagement journalism to do so effectively and measure if their efforts are worthwhile. This study will provide more technical and detailed examples of what engagement looks like at work. This research will contribute to a growing body of knowledge on how public journalism is transitioning and how this type of editor either aligns or differs from traditional journalistic and economic principles in gatekeeping decisions. This study will further explore the relationship between the business and journalistic principle sides of journalism in qualitative measurement of success in the newsroom. Finally, it will find implications for the new role of community engagement editor in journalism. 


\section{CHAPTER TWO: LITERATURE REVIEW}

Many journalists like the idea of community engagement. Vujnovic et al. (2010) in interviews with over 60 journalists, found that they see engagement as valuable because participation makes readers "loyal" to a news site, increases website traffic, and (in some cases) acts as a cost-saving measure. These are examples of business-driven benefits of community engagement. She does not, however, determine if these are metrics that journalists measure the success of their engagement efforts on. Nip (2006) noted that this rise in audience participation in journalism could actually help "engage people as citizens" and "achieve the higher goal of public journalism." These two vastly different takes of success assessment and benefit to the newsroom show the dualities of determining success in the newsroom for the community engagement editor. On one hand, the journalist sees value in its contribution to the financial benefit of the newsroom. On the other, the journalist sees value in community engagement's benefit to journalism as a principle.

In a study entitled "A Culture of Audience Engagement in the News Industry," Joy Mayer (2011) found, through survey and interview research, that journalists appreciated engagement efforts because they found them to be "good" for journalism, business, and the community. If community engagement is considered such a good thing, though, how come more newsrooms aren't employing engagement techniques? As Mayer (2011) found, the organizational and occupational culture of the newsroom often comes out as more important in day-to-day journalistic operations than audience needs or 
preferences. Outreach (reaching out to the audience instead of expecting them to come to the newsroom), conversation (talking and listening within the community outside the newsroom), and collaboration (when journalists and citizens work together to produce coverage) were three ways journalists interviewed identified using engagement techniques that were good for the news. When it came to measurement, though, few were able to vocalize concrete evidence for the success of their efforts.

Several of the most experimental journalists I interviewed worked in newsrooms that had made a commitment to audience engagement, and they said they were not yet being asked to answer for the resources dedicated to their projects. They were developing a culture of trial and error in their newsrooms, adjusting their idea of success and attempting to change the culture of their newsrooms. But they were often not being asked to demonstrate proof of success. Those days will not last. In more typical newsrooms, such as those run by the 529 editors we surveyed, resources are scarce, and a true commitment to audience engagement will require evidence of a return on that investment (Mayer, 2011, p. 45).

The hope with this study is that those hired for the position of working with the community will be able to better describe their measurements and proof of success because their job position depends on it. As Mayer pointed out, resources are scarce in the newsroom these days, and journalists are expected to prove their worth for their pay. This study will parse through how much of the assessment of success these journalists do is based on the cultural benefit to the news and its principles and how much is based on actual economic benefit to the newsroom. 
Part of why identifying engagement techniques is so hard is because there is little scholarly research out there about what exactly community engagement is. There are also many ways to refer to community engagement. Nip (2006) alone categorized five models of "audience connections," all of which fall under the umbrella of what community engagement is and what community engagement editors do. At its root, community engagement is just one of the iterations of online news journalism that has been in effect since news organizations started moving their content online in the late 1990s (Boczkowski, 2004). In a Columbia Journalism Review essay about the "future of news gurus"-Clay Shirky, Jeff Jarvis, and Jay Rosen —Starkman (2011) writes:

... the future points toward a network-driven system of journalism in which news organizations will play a decreasingly important role. News won't be collected and delivered in the traditional sense. It will be assembled, shared, and to an increasing degree, even gathered, by a sophisticated readership, one that is so active that the word "readership" will no longer apply. Let's call it a user-ship or, better, a community. This is an interconnected world in which boundaries between storyteller and audience dissolve into a conversation between equal parties, the implication being that the conversation between reporter and reader was a hierarchical relationship, as opposed to, say, a simple division of labor. (p. 3)

Community engagement, according to this prediction, exists as the way news organizations can utilize and incorporate both the journalist and the audience. As Steve Buttry, a digital transformation editor for Digital First Media and the Journal Register Co., defines it on his blog, community engagement is when news organizations, “... 
make it a top priority to listen, to join, lead and enable conversation to elevate journalism," (Buttry, 2011). He goes on to write that engagement only works if it is not an afterthought. He advocates that there must be actual listening going on, the newspaper must join in on other community-hosted events, there must be a newsroom leader willing to curate conversation, and the newsroom must engage in "multi-directional conversation." Finally, community engagement must be done to "improve our journalism."

Rosenberry (2005) expanded on methods of measuring participation in the news by the audience. He identified thirteen interactive "devices" on which to measure participation: citizen blogs, online letters, online polls, forums/message boards, discussion site links, community chats, email links to officials, chats with officials, story input, talk back, interactive storytelling, hyper-story presentation, and offsite links. He found that only three out of thirteen devices were used at more than 50 percent of the papers he surveyed and concluded that use of more would yield better political communication with readers. Mayer (2011) looked into audience engagement at newspapers by interviewing 29 journalists. One of Mayer's questions in interviews was about what success looks like in the realm of engagement and she found that many of them had no idea. She found that some had intangible benchmarks such as more civil online conversations, more community contributions, and numbers of pageviews. She attributed some of the reluctance to measure success to lack of a culture within journalism to measure anything at all. 
What sets this study apart from those previously mentioned is that it will be done with a more narrowly selected sample of journalists, specifically, engagement editors at online news organizations. The hope in this selection is that journalists in these positions will have a more advanced idea of the philosophy of community engagement. This prior knowledge will assist them in more accurately assessing how to measure why certain engagement techniques succeed and why some do not. Buttry (2012) identified on his blog thirteen leading traits (different from Rosenberry) of what makes an engagement editor including, but not limited to, managing social media accounts for the newsroom, coaching newsroom staff, leading efforts to open the newsroom to the community, recruit local blogging network, lead newsroom efforts at curating and crowdsourcing, establish community partnerships, and trying out new social tools. Using this definition of community engagement editor, this study will center on these editors as leaders in the field of community engagement. This study will hopefully contribute a more scholarly definition of what a community engagement editor is and what they do. 


\section{CHAPTER THREE: THEORETICAL FRAMEWORK}

This study used three theoretical frameworks to help provide insight and analysis to its findings. Previous academic research on public journalism, gatekeeping theory, and Bourdieu's theory of social capital will be assessed below.

\section{Public journalism}

Community engagement and the development of such editors can be seen as an outgrowth of a controversial journalism movement that originated in the early ' $90 \mathrm{~s}$ known as public or civic journalism (Lambeth, Meyer, \& Thorson, 1998). Pioneered by academician Jay Rosen and then-editor of the Wichita Eagle Davis Merritt, Jr., the two set out a new philosophy for journalism - one that places a high emphasis on creating content for the people that will help reinvigorate public life. Merritt wrote in "Imagining Public Journalism," a chapter in the book Assessing Public Journalism, a working reasoning for how to newly approach journalism. First, he wrote that public life and journalism are twined together. Second, he wrote that journalists could no longer merely provide information in an unattached way because that does not help public life. Third, he wrote that: "The objective of journalism must be to reengage citizens in public life. To make that shift, we must take two steps: add to the definition of our job the additional objective of helping public life go well, and then develop journalistic tools and reflexes necessary to reach that objective," (Lambeth et al., 1998, p. 44). In order to reach this goal, Merritt argues against detachment, which had been considered a main axiom for 
professional journalists. He writes that journalists must learn to share their values with the world because this increases their credibility. When Merritt wrote this chapter in 1998, he shared that he often got questions about the "results, accomplishments, differences" that his work with public journalism had made and that his response usually was that there weren't too many measurable changes yet because, at that point, public journalism was more about a more reader-centric cultural change in the newsroom. "Most of what can be accomplished lies ahead," he wrote (Lambeth et al., 1998, p. 45).

The definition of public journalism often takes on a democratic tone, and highly emphasizes civic action and participation in a democracy. Rosen, who also contributed to Merritt's chapter in Assessing Public Journalism, pointed out an important aspect of public journalism in that it is public. This reflection, in its symbiotic relationship with public life, means that journalism should train readers to participate. In participating in the public side of journalism, journalists "will put themselves on the side of those seeking answers to a genuine difficulty: how to make democracy work for citizens, and how to engage citizens in the real world of democracy," (Lambeth et al., 1998, p. 47). He also defines the movement as an argument about what the place of the press is and as a set of experiments that are making their way into American journalism (Lambeth et al., 1998, p. 46). Rosen echoes Merritt's feelings about journalistic credibility, writing that “credibility begins with concern,” (Rosen, 1993, p. 10). He continues:

A newspaper becomes credible by demonstrating that it cares about the quality of the public lives we lead, about the health of the political sphere in a particular community, about the demand democracy makes on all of use to dwell in public 
time. Credibility as care and concern doesn't refute the importance of distance and detachment, which are rooted, after all in a genuine concern for truth. But the new view of credibility recognizes an even deeper truth: that journalism cannot remain valuable unless public life remains viable.

This outlook represents a major cultural shift in journalistic thinking, one that during the heyday of public journalism was heavily criticized, possibly because it did not yet have a set of measurements to test its success. In Getting the Connections Right, Rosen writes that by 1995 , over 150 news organizations had tried some form of public journalism and that the fast rise of the movement brought trouble because experimentations had gone too many different directions (Rosen, 1996, p. 51).

Philip Meyer introduced a remedy to this situation in the last chapter of Assessing Public Journalism entitled "If it Works, How Will We Know?" Here he introduced the idea that public journalism's criticisms began with a lack of definition for the movement (Lambeth et al., 1998, p. 252). This led him to the thought that definition would lead to better measurement of the practice. After definition, he remarked on several ways that researchers could measure it: identify tangible elements of public journalism and see how often they proliferated in coverage, study public journalism's effects on the community the journalists are serving (does it increase public participation in citizens?), and look to long-term measures such as the strengthening of community ties, interpersonal trust, and trust in institutions (Lambeth et al., 1998, pp. 258-268). Meyer also made a connection between public journalism and measuring economic benefit to journalism institutions: "Public journalism's failure to show immediate economic 
benefits could prove a major disadvantage. ... Because there is more than one way to do public journalism, it will be important to know what ways do the most at the least cost," (Lambeth et al., 1998, p. 270). These measures can serve as a jumping off point for questioning about how community engagement editors measure the success of their work and understanding what they do measure as success.

As for how this civic-minded journalism gave birth to community engagement positions at newspapers, newer texts on public journalism give some insight. In Twilight of Press Freedom, John C. Merrill argues that "a new social paradigm of order, harmony, and security in community is replacing the old paradigm of freedom and individualism," (Merrill, Gade, \& Blevens, 2001, p. xv). The authors of the volume argue that society is moving away from the values of European Enlightenment towards communitarianism (ordered and harmonious community) and that journalism is reflecting that movement in public journalism. "Public involvement is the new media objective. As the concept of journalistic autonomy fades, so ordered and responsible journalism is arising, dedicated to the public good and not to private interests," (Merrill et al., 2001, p. xvii). The arguments in the book widen the scope of the movement through historical perspective. Instead of simply focusing on public journalism as a means to the end-goal of civic participation, it blows the movement up to relate it more broadly to a movement that prizes community and community ties more than anything else, including individual freedom. It notes that public journalism's goals also included connecting people with their newspapers and their communities, in addition to public life. 
[Public journalists] want a press that is altruistic, not egocentric; they want a press that is community oriented, not institution oriented; they want a press that places more emphasis on its responsibility than on its freedom; they want a press that increases the citizens' political participation; they want a press that encourages public conversation about serious matters; they want a press that increasingly brings people together; they want a harmonious and noncontentious press that fosters community stability; they want a press that not only informs the public but engages it. In short, they want the focus shifted to the community and taken off of the press itself (Merrill et al., 2001, p. 117).

This quote represents the shift to a wider description of public journalism that sets the stage for community engagement to come into play -if the focus is on the community, doesn't it make sense for journalists to be concerned with how the community relates to their paper and the connectedness they feel with it? Merrill also points out for the first time that public journalism has fostered the idea of breaking down media elitism, that in fact, "everybody can be a journalist." Herein lies some tension between public and legacy journalists - if everyone can be a journalist, why is there a need for professional ones? As Lewis (2012) argues, journalists are confronting the conflict between professional control and open participation, which is a clash going on in many creative fields today. Community engagement editors can be seen as media professionals renegotiating that journalist-audience interplay.

Public Journalism 2.0 further bridges the divide between how public journalism was originally conceived and how community engagement editors came to be. Written 
much later than previous literature, in 2010 , it adds to public journalism scholarship by placing it in the era of Internet and digital-first news organizations. It affords that though traditional public journalism ideals had been declining in popularity (practices take too many economic resources), the Internet and the slew of new technological tools that it provides are a basis for public journalism's resurgence (Rosenberry \& John, 2010, p. 4). The book links citizen journalism and public journalism in order to make "citizenengaged journalism," (Rosenberry \& John, 2010, p. 5). In the second chapter of the book, James K. Batten speaks to the vital connection between newspapers and communities, writing that community attachment is the most influential area affecting readership today. This determination came after a survey of more than 16,300 readers and non-readers of newspapers showed that people who felt a connection to the place they live were twice as likely to be regular readers of newspapers (Rosenberry \& John, 2010, p. 15). This gives public journalism a new focus: reflecting, including, and strengthening community in the news product itself in order to increase readership. That economical reasoning calls for measurement to see if readership is being bolstered by communitycentric journalism. Batten himself wrote that the problem with journalists in 2010 was that they were disconnected from communities they served because of the transience of the profession (Rosenberry \& John, 2010, p. 17). This might be seen as the call for a less transient, more public face of the news product: a place that is filled by the community engagement editor.

Joyce Nip has done extensive research on public journalism and was the first to come up with a typology of audience participation in newspapers that she thought defined 
the second phase of public journalism (Nip, 2006). Those types were based on the extent of participation by ordinary people and went from traditional journalism, to public journalism, to interactive journalism, to participatory journalism, to citizen journalism. "Unlike in the first phase of public journalism, where news organizations initiated the engagement, in this second phase, the public themselves hold the possibility of taking initiative," (Nip, 2006, p. 230). In a section of Public Journalism 2.0 entitled "Routinization of Charisma," Nip points out that the biggest challenge this second phase of public journalism faces is taking the practices from special projects to day-to-day operations within the newsroom: “...the question is how to get news organizations to build in more of the features of audience engagement, and to use them toward strengthening the community/public and democracy," (Rosenberry \& John, 2010, p. 145). This is an idea that Rosenberry echoes in a later chapter entitled "Civic engagement and Online News Organizations," where he writes that the biggest barrier to public journalism is that new frameworks of coverage that include conversation with readers require journalists to adopt new roles. "The traditional description of an editor's job involves fact-checking and re-writing reporters' stories, not recruiting citizen bloggers and moderating online discussions," he writes (Rosenberry \& John, 2010, p. 157). He points out that tradition in journalism serves as inertia and could slow that process down. The creation of the community engagement editor position at newspapers could be seen as an institutionalization of the concepts of public journalism. 


\section{Gatekeeping theory}

Gatekeeping has changed much since its first proposition by Kurt Lewin (1947) in regards to food habits and group dynamics, transitioning to a theory used by journalism researchers to understand how journalists make decisions in their day-to-day work. "Gatekeeping begins when a communication worker forms information about an event into a message," (Shoemaker \& Vos, 2009, p. 22). From there, the process of gatekeeping occurs as different "forces", such as personal background and organizational structure, influence how individual journalists, or "gatekeepers", as they shape, display, time, withhold information, or repeat the message (Donohue, Olien, \& Tichenor, 1985). The first to apply gatekeeping concepts to journalism was David Manning White, with his study on the subjective news selection decisions of "Mr. Gates," a wire editor of a small newspaper (White, 1950). Studies after these looked at gatekeeping both from an organizational and individual perspective. McNelly (1959) pointed out that there are several individual gatekeepers in the actual flow of news that input their selection decisions before content is published. Bass (1969) went further in delineating the role of the individual gatekeeper as either a news gatherer (reporter, writer) and news processor (editor). Gandy (1982) contributed to gatekeeping research in that he found that different “information subsidies," such as public relations firms, can and do influence journalistic gatekeepers from outside the newsroom by presenting information attractively to them. This brings up a point that this study seeks to explore: how journalists' relationships with the outside world influence their gatekeeping, or decision-making. 
As the discussion of public journalism affirmed, one of the things that makes community engagement editors different is their focus on the community and away from organizational structure or personal beliefs and value they put on tapping into the interests of community in their news coverage. As Shoemaker and Vos $(2009$, p. 47) point out, "The emergence of public journalism reflects a shift of journalists' roles with more emphasis on community involvement in local news." Aaron Barlow, in a chapter entitled "The Citizen Journalism as Gatekeeper" in Public Journalism 2.0, writes that, because of public journalism and citizen journalism, there has been a renegotiating of the traditional gatekeeping roles of journalists and, now, of the readers in connection with them.

The role of the amateur...lies in simultaneously signalizing and fact-finding. Meanwhile, the role of the journalist moves toward truth-finding through information vetting and final presentation.... the journalist is holding on to a reduced gatekeeping role that continues to focus on being a protector of community standards and a provider of on-call expertise. (Rosenberry \& John, 2010, p. 50)

Bruns (2009) also noted this change for online news editors in general, referring to journalists no longer as gatekeepers but as "gatewatchers" because of their role in observing and sorting through material already sorted by readers. The community engagement editor's relationship, which is different than that of a source and journalist, needs to be explored for its influence on the decision-making of these editors. Does having more of a connection with the audience shape how engagement editors make 
decisions about the community engagement journalism they do? Is that different from how editors normally make decisions?

Traditionally, as Shoemaker and Vos (2009, p. 53) point out, journalists have only had an "abstract, second-hand" idea of what the audience desires of the media. Gans (1979) seminal Deciding What's News, pointed out that traditional journalists often do not accept market research on the audience. The study showed that journalists believed they knew better than the audience about what the audience wanted and needed (Gans, 1979, p. 235). Gieber (1963) explained that, though he believed journalists knew little of their audiences, there were two kinds of personalities in the newsroom that may explain how gatekeeping decisions are made. He found that "introjective" journalists, less in number in newsrooms, internalize the feelings and values of their audiences and that influences the decisions they make. "Projective" journalists, accounting for the majority of journalists in the newsroom, believe audience feelings mirror their own and, thus, make decisions and expect the audience to line up with them. In a more modern study, Napoli (2003) used the terms predicted and measured audience to describe the media's understanding of their readers - because of uncertainty and limited resources, gatekeepers rely on measuring what the audience wants in limited sample and predicting (reproducing) what they want as well. Shoemaker and Vos (2009, p. 78) wrote that the predicting is what forces gatekeeping decisions. This background into audiencejournalism relations in regards to gatekeeping show that the relatively new position of community engagement editor and the decisions those editors make deserve to be explored to see how they fall in place in this historical perspective. 
In the analysis of an individual's gatekeeping, Shoemaker and Vos (2009) put forth several areas for analysis including personality, background, values, professional role conception, and decision making. Because this study will be questioning journalists about their assessments of their community engagement journalism and how those assessments factor into their decision-making, it only makes sense to apply decisionmaking concepts of gatekeeping to the analysis of their responses. In interviewing community engagement editors and analyzing their gatekeeping process, the previous literature on traditional gatekeeping roles will help to see if the influence of connection with the audience and community has any effect on journalistic decision-making. As Shoemaker and Vos (2009) set forth in their examination of gatekeeping in Gatekeeping Theory, "The mass media provide a conduit through which new ideas and groups who introduce them can reach the larger public," (Shoemaker \& Vos, 2009, p. 5). It is imperative we understand how this new type of editor makes decisions based on its relationship with the audience, for further understanding of the relationship between the people and mass media.

\section{Bourdieu's capital}

The twentieth century sociologist Pierre Bourdieu spent the majority of his scholarly life exploring the concepts of power relations through exploring the experience of the individual and the influence of external social structure. One of his most important contributions to media studies is the idea of capital, which he defines as: 
... accumulated labor which, when appropriated on a private, i.e., exclusive, basis by agents or groups of agents, enables them to appropriate social energy in the form of reified or living labor.... It is what makes the games of society - not least, the economic game - something other than simple games of chance offering at every moment the possibility of a miracle. (Bourdieu, 1986, p. 241)

Essentially, the presence of many different types of capital and the determining of the importance and weight of these types is what enables humans to make decisions because they choose to do something based on what they think their actions will contribute to the capital (power) they privilege. There are types and subtypes of capital that Bourdieu identified but the most important to this study are those of economic and cultural capital. Economic capital is "immediately and directly" convertible into money. Cultural capital like general knowledge, artistic sense, and technical expertise can be converted into economic capital on certain conditions. Bourdieu believed that, in relation to journalism, the need for economic capital acquisition takes away from the need for cultural capital (Bourdieu, 2005).

In her dissertation, You Li (2012) looked at the balance between economic and cultural capital in a medium-sized family-owned newspaper and further tied Bourdieu's ideas of capital to the functioning of online newspapers.

Newspaper is not only a social institution that serves watchdog and educational functions, but also a business entity generating economic return. The newspaper product thus assumes both the nature of a public good and the nature of a 
commodity. In an ideal word, newspapers should produce quality content that meets both journalistic requirements and financial expectations. (Li, 2012, p. 2) She found through her triangulated case study that economic capital did affect resource management in the newsroom but that had nothing to do with the newspaper's commitment to journalistic cultural values/principles. In fact, she also found that content that "fulfilled the journalistic missions" contributed to advertising revenue. She also posited that a better tie between business and mission/editorial needs to be built for newspapers' economic viability in the future.

As the literature on public journalism and community engagement shows, there is a tension in the balance between the business and editorial goals and needs of community engagement. On one hand, there exists a lofty goal of serving the public well and fostering a sense of community. On the other hand, there exists the need to justify the viability of the newspaper through meeting business benchmarks. This study will determine what community engagement editors believe is the balance between these two goals. Because their time resources are put into working with the community, there must be expected gain. This study will looks at how these journalists assess and measure the engagement work they've done. Do they assess based on an economic or cultural capital benchmarks? The balance and tension between the two will be interesting to hear the journalists vocalize. More interesting, however, is the potential implications learning about this balance might have for the news industry. This study will hopefully determine if community engagement editors do process their success differently than others in the industry. 


\section{CHAPTER FOUR: RESEARCH QUESTIONS}

Using the theoretical framework of gatekeeping, previous research on public journalism, and Bourdieu's ideas of capital, this study aims to academically define what a community engagement editor's job duties are, how they determine if the editors' work is successful, and how those things influence editors' journalistic and economic values. This will hopefully add to public knowledge about what this type of editor contributes to the journalistic world. The following research questions will serve as guideposts for what the study sets out to accomplish:

1A. What is the conceptualization and reasoning behind the position of community engagement editor at online newspapers?

1B. What are the daily activities and goals of the journalists filling this position?

2A. How do community engagement editors assess and measure the success of their journalism?

2B. How does this assessment influence the concept of gatekeeping decisions?

3A. To what extent do community engagement editors assess their journalistic and economic capital?

3B. How do they view their relationship to traditional journalistic principles? 


\section{CHAPTER FIVE: METHOD}

This study used an approach of in-depth semi-structured interviews to question community engagement editors at digital news organizations on their job duties, the assessment of their journalism, how that assessment factors into their decision making, and their journalistic and business values.

\section{Procedure}

This study interviewed ten engagement editors, or editors at digital news organization that went by a different title but serve as a liaison between newsroom and community, to explore this relatively new position and how journalists function in it. These in-depth, semi-structured interviews lasted between (at shortest) 30 minutes and (at longest) one hour and 15 minutes. A pre-interview questionnaire (see Appendix A) with a written list of simple questions about the job title, job description, three most common engagement techniques, and demographic information was sent to interviewees for completion prior to the interview. This study used a theoretical sampling approach to choose a certain type of journalist for interviewing (those dealing in community engagement) and were recruited after first viewing their profiles on LinkedIn to find relevant editors. Fifteen editors were then sent emails about participation in the study (see Appendix A). If there was no response to initial contact, a follow-up email was sent (see Appendix B). Nine editors responded to this recruitment, and one other was found through snowball recruiting (asking a responsive editor for suggestions of who they thought would be good to interview). Questions during the interview revolved around the 
types of engagement activities the editors are doing, the success of engagement activities, the measurement of the success of engagement activities, and how those measurements and interactions with the community influence their news-making decisions (see Appendix $\mathrm{C}$ for the list of interview questions). The ultimate point of these questions was to get at what ways this type of journalist determines that their work is successful and how this shapes editors' newsroom decisions.

The interviews remained semi-structured because, though there was a list of questions to get through, the interviewer tried to "maintain the casual quality found in unstructured interviews," (Berger, 2000, p. 112). This method helped highlight the understanding of attitudes, motivations, and depth of personal assessment of community engagement editors. Because those being interviewed were scattered nationwide, the interviews with the participants were done over the phone. Interviewees were informed that their names and the publication they worked for would be included in research material. The thinking here was to be able to highlight detailed information about the differences in their work without diluting examples to obfuscate the identity of those interviewed. To ensure accurate coding of the interviews, each was recorded using the computer recording application Audacity and carefully transcribed into a Word document until further assessment began. For analyzing the interviews, the constant comparative method was employed to code and analyze these works (Glaser \& Strauss, 1967) about how community engagement editors assess success and make decisions based on that measurement. 


\section{Sampling}

This study used a theoretical sampling approach to find research participants. This type of approach allowed the researcher to select a certain category or journalist to study based on their relevance to the research questions and theoretical positions (Mason, 1996). Theoretical sampling means that a small sample can be chosen that will represent a wider population based on "particular processes, types, categories, or examples which are relevant to or appear within the wider universe," (Mason, 1996, p. 124). Using the three categories of setting, research focus, and generalizing set out by Silverman (2010), this study winnowed down the subjects of research from the broad "journalist" to community engagement editors at online news organizations in the United States. It should be kept in mind that some of those chosen for interviewing did not have the exact title of community engagement editor. As Nip (2006) pointed out, the people who do public journalism work (or more recent incarnations of it) go by many different titles, due to the lack of early definition for public journalism and variety within what these type of journalists do. If an editor did not have the exact title of engagement editor, but espoused the principles of valuing the community in ways like public journalists do or fit into the position that Buttry (2012) described, these editors were also qualified to be participants in the study. The choice of editors was not without thought: editors chosen for this specific of a position already had a preliminary understanding of the philosophy they were interviewed about and analyzing their work toward, which started interviewee and interviewer out on more even ground. This study interviewed engagement editors who work for an online newspaper that had or has a print outlet in addition to the online news 
site with the hope that editors who were tied to a print outlet in some way would allow the journalists to make more salient comparisons. The hope of this study was to find engagement editors who had been working at their job for a year or more, in order to ensure they have had time to experiment, execute, and reflect on their engagement work. However, a few of the editors interview had been working in their positions for less than a year, due to the recently created nature of the community engagement editor position. Those who had worked their position for less than a year had held a position either at the newspaper or in another engagement position prior, however, so they were still able to come into the interview with some prior philosophical understanding of community engagement on the whole.

This study primarily used the networking service LinkedIn in order to find the names of people who had job titles similar to "community engagement editor," "community outreach editor," or "community manager" at digital news organizations. This returned a variety of positions and resulted in interviews with the following journalists either through immediate contact or, later, through using the snowballing technique:

Shahid Abdul-Karim - 39, New Haven Register, Community Engagement Editor, New Haven, Connecticut.

Martin Beck-48, Los Angeles Times, Reader Engagement and Social Media Editor, Los Angeles Times, California.

John Brewer-36, St. Paul Pioneer Press, Community Engagement Reporter, St. Paul, Minnesota. 
Jennifer Connor-24, The Lansdale Reporter, Community Engagement Editor, Lansdale, Pennsylvania.

Maryanne MacLeod-44, Macomb Daily, Community Engagement Editor, Clinton Township, Michigan.

Holly Norton - 37, The News Journal, Community Engagement Editor, New Castle, Delaware.

Stephanie Ogilvie - 36, Roanoke Times, Social Media Editor, Roanoke, Virginia. David Plazas - 36, The News Press, Engagement Editor, Fort Myers, Florida.

Terry Price, Jr.-33, The Patriot-News, Lead Engagement Specialist, Harrisburg, Pennsylvania.

Sarah Velasquez - 28, The Buffalo News, Digital Engagement Editor, Buffalo, New York.

One can see that this sampling approach provided a fairly even distribution of ages, genders, and types of digital news organization worked for. After compiling a list of names, the researcher either used contact information self-provided by LinkedIn users or found their contact information on the website of the newspaper they listed they worked for on LinkedIn. After a preliminary email to those on that list was made to assess interest in an interview, a snowball strategy to obtain more names and references of editors who are well regarded in their field of audience engagement was used, though this strategy only turned up one responsive editor. In both cases of contact, a pre-interview questionnaire was used in the recruitment email requesting basic name, position, job 
duties, news organization name, and demographic information was used and recorded and excel spreadsheet for later use.

Previous sampling size in interviewing journalists on their decision-making varies markedly. Mayer (2011), whose subject matter most closely resembles this study's on the topic of audience engagement and is also a community engagement journalist herself, utilized 29 interviews with journalists, one case study, and a survey of over 500 editors and journalists. Ahva (2012), who studied public journalists and professional identification, interviewed several journalists in three different-sized newsrooms in both groups and individually. Lessman (2007) did ten "informant" interviews with journalists in community news organizations on their decisions making process and followed that up with 20 short, secondary "ethnographic" interviews with people surrounding the decision making process but not as the primary actor. As these three studies show, sample size varies, but by aiming for 10-20 participants, this study fell well within the range of number of interviews done before in similar research. Although the range of sampling size may seem large, as Mason (1996, p. 136) pointed out: “Theoretical or purposive sampling is a set of procedures where the researcher manipulates their analysis, theory, and sampling activities interactively during the research process, to a much greater extent than in statistical sampling." For this study, this meant that sampling started out small but snowballed until saturation was reached and editors' answers were repetitive, which was found at ten interviews. 


\section{CHAPTER SIX: FINDINGS}

The findings of this study have been broken down into three parts. First, this thesis will discuss what a community engagement editor is and the variety of newsroom duties that position includes. Secondly, this thesis takes a look at how these journalists assess the success of their work and how that influences what they continue to do. Thirdly, this

thesis will address how these journalists approach the balance of journalistic and business principles in their daily work.

This study used interviews with ten journalists doing engagement work at online news organizations that still have a print edition across the country. Interviews looked into how the journalist got into their work, what daily activities and goals of the position are, how they assess their work, and how they balance business and journalistic values in day-to-day decision making.

\section{What is a community engagement editor?}

The introduction of community engagement editors into the newsroom is a relatively new development across the country. Of the ten interviews done, the longest any editor had been working in the position had been four years, with most others working significantly less than that, around one to two years. Most editors were promoted from within during a corporate restructuring and reemphasis on the reader-which most often took the form of increasing social media use. Only one editor had been hired from the outside, Terry Parris, Jr., to manage a community engagement team. Those that were 
hired from within came from an editorial background-either in reporting or editing. The majority of editors indicated that the position was created in a top-down decision from corporate and that skillsets as people-pleasers, experimenters, social media savvy, and multi-taskers. As John Brewer put it, "I did a lot of man-on-the-street work already. I was experimenting with different social media tools, different online reporting tools. It kind of fit what I was already doing...I think they gave me the gig because I was outgoing and friendly." A few editors talked about the conception of their position as more a of a jointcreation decision or as a decision from direct supervising editor. In those cases, a sense of boredom or wish to try something new was paramount. Experimentation and evolution in the digital world was a key aspect for most at the inception of the position, though how that has evolved into today's work has certainly changed. "We're constantly evolvingwe were in the midst of trying to figure out what our digital staff looked like," Martin Beck said. "We had just merged the print and web newsrooms. We were looking to refine what those operated like." As Stephanie Ogilvie put it: "The story of all this, if anything is that this job keeps evolving. It seems year after year, there are new needs. I just kind of morph to fill those needs and try to match what I think I'm good at with where I see gaps."

This evolutionary tendency often left editors with a loose definition of position and what would be required of them in the role. "I was given goals," Sarah Velasquez said. "My two editors crafted a loose job description with a set of goals they wanted me to accomplish and properties they wanted me to manage." For Velasquez, those goals included increasing engagement between news brand and reader, increasing engagement 
between reporters/editors and the audience (putting a face to the name), determining if live blogs and videos are worthwhile, helping increase search engine rankings for articles, and monitoring the news brand on social media platforms. David Plazas came into the position with the similarly lofty goal of exploring audience markets more and finding "passion topics" for the community. "That is part of the story of engagement, we can no longer be separated from the community, we really have to understand their habits," Plazas said. These goals, though lofty, are pretty well articulated compared to others' descriptions of their goals. Most were given the idea of drumming up "better insight into the community" or "expanding the digital footprint of the newspaper." Beck and Ogilvie both mentioned the goal of looking at the news product from the viewpoint of the reader. "You know, many newspapers traditionally have an ombudsman who is an advocate for the print reader," Beck said. "I thought we needed that on the online side as well." The most common goal articulated by bosses, however, was the idea of increase-increase in audience numbers and an increase in social media followers. “There weren't really other goals, which is something that actually frustrates me about my position," Jennifer Connor said. Those journalists who were able to describe their goals outside of the idea of "increase" alone seemed more confident and pleased with their job and their ability to assess their own work.

The defining characteristic of the job that every journalist indicated is that it requires being able to juggle many totally different things at once and to be able to "build a bridge" not only between the community and the newsroom but also between areas of the newsroom itself. As Terry Parris, Jr. said, "I think my job is to build a bridge between 
the people and the paper. It is finding ways to connect community and reporters-share stories, help each other do better journalism and public service." The easiest way to understand what a community engagement editor does it to look at a list of duties mentioned as day-to-day activities on the part of the editors. These activities fall under five categories of work: social media, community outreach, reporting/submissions work, audience research, and newsroom collaboration efforts. Delineating categories of work can be difficult, however, because the job duties associated with each are not mutually exclusive. An editor, for example, may use social media job duties and skills to assist in reporting and submissions work or audience research may be part of community outreach. Many skills and duties of the community engagement editor are interchangeable, but these five categories represent self-reported descriptions of different types of work.

\section{Social media.}

Every single journalist mentioned that their position dealt in work with social media. This meant everything from researching current trends in social media and experimenting with them, developing a social media strategy or voice for the newsroom, listening in what the community is talking about, writing social media posts (both for headline dissemination and for the sole purpose of creating conversation), and moderating community conversations around the newsroom's social media accounts and commenting systems. The purpose of this work is generally meant to drum up conversation around content and find new story ideas or viewpoints to be reflected in the news product. "We're looking at national stories and stories on our site and we want to 
figure out ways to get people to comment on this content," Parris said of what he calls "reaction posts" on social media. "Its our way of saying, 'We want you to talk. We want to have a conversation with you.' We do this type of thing regularly." Beck, who manages a team that works with the Los Angeles Times' social media accounts said: "It's a matter of identifying stories we think will with resonate with our audiences. Another part of it is making sure we're responding to messages from readers-looking through responses, questions, reactions wherever they are happening and making a determination about what requires a response." Identification of stories that are conversation starters for the community on social media and response to those who reach out to the newsroom were described as the basic, integral duties of community engagement editors on social media.

The social media aspect of a community engagement editor's position often entails translating what works well in a story to what the different audiences of social media platforms want. For example, several editors mentioned the need for images in Facebook posts and wit in Twitter wording. The social media component of the job is often the most ever-present activity of the day: "When it comes to social media, like Twitter, Facebook, Reddit, and Google +, I am constantly monitoring and updating those accounts, "Velasquez said. "I always have Tweetdeck open, my personal email and Facebook, and Buffalo News open. So that is 9 to 5 . Between all of that, among other interactions, I respond to readers' concerns." Velasquez is also often working with the newsroom's new CMS system, submitting tickets to the development team to fix things on the website, and crafting posts several times an hour for Twitter and Facebook. 
Commonly among these journalists, social media skillsets are intertwined with other digital skills such as content placement and SEO knowledge, which makes work overlap into other digital duties.

\section{Community outreach.}

Getting out of the newsroom and into the community itself was another category of job duty that many of the journalists interviewed made reference to. This could take the shape of organizing events or forums for the community either inside or outside the newsroom, public speaking, being a personality in the community, being the face of the newsroom at community events, and being the outgoing person that audience members' could approach to chat with. Norton said that this part of the job is all about, "the whole transparency of being a writer and editor and newsperson and living in the community. I looked at it as a mission of ours to break down the wall between reporter and community and open up the newsroom." For Norton, this took on the guise of organizing three workshops, called “social media mash-ups", about LinkedIn, Facebook, and Google+. The newsroom held the event in their building for audience members to come to for free. "It was exposure for me as a person people could contact on behalf of the newsroom," Norton said. "It's kind of like PR in a way. Marketing our brand and being a friendly face."

While some editors noted the promotional aspect of introducing oneself to the community as a representative of the newsroom, other editors found a reciprocal purpose in being out in the community that dealt with listening in on what community members found to be important. Abdul-Karim, who considers himself an activist in the community, 
is devoted to "canvassing the community" in local establishments and chatting with people about what issues are important to them. These conversations he either turns into an invitation to write for the news product or an invitation to participate in a community forum on the topic he is organizing. He considers his most successful work those community forums, which take several weeks to coordinate. It involves writing stories to promote the event, getting the participants to come for their photos for the promotional materials, setting up the place where the forum will be, figuring out chairs and sound system, preparing moderation questions, setting up a livestream for the event. MacLeod runs a community media lab for her news product.

By appointment, members of the community can come in for individual instruction on how to promote their product through Twitter, Facebook, that sort of thing. So I work on making appointments with various sources and people I meet through social media to come in and do that. The other part is to plan workshops that our staff and others lead in the new lab on community contribution, social media, blogging, and those sorts of things.

What MacLeod does through the media lab (bring the community in to teach them how to use media in different forms of social media, press releases, blogging, etc. either for personal or business purposes) may seem counterintuitive to journalistic outreach for outreach's sake but represents and understanding of offering information on what people want to know so they'll come to the newsroom and MacLeod can reach out to them as potential community contributors or subscribers once the lab has their attention. 
Brewer takes his community outreach work on the road in a mobile community lab, a car outfitted with reporting and outreach materials, in which he attends events where people are gathered such as the Twin Cities marathon or Minnesota Vikings training camp. He spoke of a winter treasure hunt in St. Paul where people come out to the city's parks in the dead of winter. "A lot of it was just bringing snacks so people had a place to come warm up, talking about the hunt, and collecting some stories." While every event may not churn out a story for Brewer (who holds a unique title of community engagement reporter), there are other benefits to being out and about in the community besides getting on the front page. "I listen to a lot of stuff I'm never going to use," Brewer said.

You go down avenues that don't pan out. For awhile we talked about what the bar is for what makes a story and do we need to lower it for what makes these conversations I have with people into stories. The difference is I'm not creating something for print. I'm just going out there and talking to people, getting the name of the newspaper out there. It's a lot of listening. Not everything leads to coverage. Hopefully, though, some of it pans out into better coverage of some event or area.

Brewer vocalizes the idea that outreach is not always about producing an immediate news product - its about gathering ideas for future stories, showing the newspaper is invested and out in the community, and occasionally getting stories that wouldn't necessarily be considered newsworthy into the news product just because readers would like to see their voices reflected. 
Sometimes outreach also takes the simple form of just going out and about to test the pulse of the community. Parris was very adamant about his work outside of the newsroom, not just in his office, doing this kind of work:

Yesterday, I was out, walking and talking to community members. That's part of community engagement too, not just sitting in front of Twitter doing @ replies. If you're not talking to the community to improve journalism, you're not doing it correctly. A lot of people thing, 'Oh, let's put a poll on this, let's send out a tweet, put it on Facebook.' That can be part of it, but I feel it is a larger, deeper, and bigger part of storytelling in journalism to be out there as we move forward.

For Parris, this meant going out and holding "mobile cafés" where he and his staff go to local coffee shops in the area and "put a face to the newspaper." They hand out index cards to people asking them "What's affecting you? Good and bad?" He also has plans for an "open newsroom" where they take the newsroom to a community place and have a back-and-forth with community members about what the newspaper is doing right, what could be done better, etc. "We can sit in the newsroom and speculate," Parris said. "We can look at numbers. We can see what the community is reading. But there are a lot of things we don't know to be covering and the only way to figure that out is to talk to the community. If it weren't for them, the stories wouldn't exist." Here, Parris is explaining the need to be in-person with community members to, in essence, fact-check what data is telling the newsroom that the audience likes. While analytical data about reader habits is vast, in-person outreach may check data-driven decision-making to ensure the newsroom stays in touch with what readers want. 


\section{Reporting/submissions contributions.}

Community engagement editors often find themselves taking on the role of more traditional newsroom jobs or finding ways to insert what they do into those traditional newsroom processes. This is seen in the editors contributions to reporting which is done through writing stories (both promotional and reportorial), finding reader submissions, editing submissions, reflecting reader voices in the paper, connecting reporters with sources, and fleshing out reported stories with more community input. Essentially, they call upon already-grown community connections to help contribute to newsroom coverage. One way this is done is through crowdsourcing-or calling on community members' to contribute to a report - which Ogilvie spoke of when she reflected on her most successful engagement work on the past year:

A year ago we had a wall of wind come through. It blew down many trees and power lines and many of us were without power for a week. I remember we covered it like we're always covering things - here's what officials say, here's pictures of trees down, here's how to keep safe, but then a situation direction got ahold of our editor and said 'You should ask people "Who has ice to keep perishables cold?", That's what we did. It was incredibly helpful and people embraced it. People were reporting and helping each other.

Ogilvie found that in a disaster situation, people were ready to contribute to community knowledge and betterment in the form of sharing where they knew ice was still available to keep perishables from rotting. This was crowd-sourced reporting plain and simple. 
Curating community contribution to reporting can happen either as an addendum to other reporters' work in interviewing or as standalone submissions that are apart from work other reporters' in the newsroom are doing. With addendums embedded in other journalists' stories, community engagement leaders in the newsroom usually act as a liaison between source and reporter - they'll ask a question on social media or check to see if someone they talked to is willing to be followed up with by a reporter. "My goal is to find stories we wouldn't otherwise know," Brewer said. “A lot of stories come from city council agendas. A lot of people as a reporter you don't interact with. My goal is to collect those stories we wouldn't get sent. ...Sometimes what I'm trying to do is collecting names and numbers and having a list of people I can call for a perspective on an issue." This is often done through applications such as American Public Media's Public Insight Network or even just a written database of people that could be called upon at a later time. Most journalists said that they spread this information to other reporters in the newsroom, though it is not as often as one might think. Being able to share gained knowledge of the community within the newsroom often depended on a feeling of buy-in or interest from other reporters or editors, which will be discussed in the newsroom collaboration section. Most of the time, engagement editors' help with reporters' stories is often informal. After going to a low-energy event that did not turn into a story, Brewer said:

Even after talking to folks at [this event], I told the reporter, 'Hey, this is the feeling I'm getting. You might want to think about this the next time your report on it. The other thing I'm proactive about is inviting other reporters to go out with 
me in the mobile media lab. A lot of reporters don't like man-on-the-street reporting. I love it. I use it as a resource to help them break through the barrier with the community. It's not like every week I have tips to pass along, but I often have color to pass along.

While Brewer did not give the reporter he spoke with a list of quotes or contacts for sources, he gave the reporter information on a place he could start or, in academic terms, already began the process of framing and gatekeeping stories that Brewer thought the reporter should or could focus on. The act of inviting a reporter along to do work in the community differently (man-on-the-street) was also seen as a way to influence reporting by opening up the reporter to knew types of responses and experiences.

In creating stand-alone content from community contributions, there are two typical types of submissions - one is a longer form submission that is usually curated and edited and the other is a shorter reflection of community thinking. Parris talks about the difference between the two, noting that he encounters both kinds in his day-to-day work. One avenue, he calls "long-form community storytelling." Specifically, this is when the newsroom looks for people in the community to help tell the story of an issue. This includes soliciting reader contribution to issue-stories with a Google form embedded in a story about the topic. Parris cited and example of a package the newsroom worked on called "The Cost of Coming Out."

We had a reporter working on a multi-series piece but we wanted to solicit longform contributions. We're working on this story and we really want to know what a person's cost of coming out, so we asked. We were flooded with first-hand 
accounts of what it meant. So what we did was have the reporter's story and then gave him the stories from people who submitted their responses and he went through and checked and verified their stories. Then we took those testimonials and sprinkled them throughout the traditional story. Really powerful stuff that we wouldn't have gotten without the audience engagement aspect. In the end, he did seven posts and we had eight testimonial posts. Half of the package was stories from the community.

This type of assistance in reporting does not look all that different from traditional reporting - getting stories from community members to back up an article's information, argument, or point. To the reader, the difference is that the engagement editor helps find these sources and later passes them off to the reporter working on the story, rarely getting the byline that the reader sees because it either goes to the reporter or the community member who contributed.

Long-form reporting assistance generally takes a lot of time to solicit, edit, and collaborate over so it is more rare than the second type of submission that Parris calls "low-hanging fruit." This type of submission is usually about quick responses to questions that don't require a lot of explanation. "We want people to send us stuff, send us stories, send us photos. Comment on, have that conversation." While Parris prefers the longer-form storytelling, he sees the purpose of both: "I think we can affect most change with the long-form. The other two parts about introducing and showing that you are part of the community as well. We want people to become part of the paper. We're part of the community, we think they should be part of the paper." This short call-and-response type 
work was more common among more editors, because of the ease of doing it over social media and the low commitment on the part of the reader. Beck spoke of this kind of work one of the members of his team is doing on social media with the hashtag \#mydayinLA, where both newspaper staff and readers share pictures of what Los Angeles looks like to them. "You see a really rich vision of what's going on in L.A. on any given day. It's a good example of someone really listening to our audience and asking them to participate then acknowledging and encouraging them to participate. Its not directly increasing traffic to our site but it is creating a micro-community, which is rare for us."

Jennifer Connor verified the difference in submissions/reporting work as well. On one hand, she pointed out that she asks questions of readers just to get conversation going and sometimes those responses get woven into reported stories. The second kind of example comes from her experience curating the "Lansdale Love" blog for her newspaper where she collects feel-good stories from the community. "We target it as stories with positive news going on in the community. I'll tweet and ask people to share their feel-good stories with us." She cites two stories that were longer form, one about a little girl with a neuro-muscular disorder whose family needed help raising money for wheelchair accessible van. The other dealt with a "sweetest thing" contest about writing in what the sweetest thing your significant other has done for you for Valentines Day. For MacLeod, a big goal of her community media lab is to turn attendees into reporters and submitters in their own right. She sees this community contribution as a substitute for traditional reporting almost completely. 
The whole point is to bring the community to the newsroom. As newsroom staffs dwindle, we have to find new ways to get the news out. While our reporters will still cover breaking news, some of the festivals or feature stories, we're trying to get community contributors to put together relevant press releases and then we edit those and put them online. That's the trust of the media lab-teaching them to put together material that we can then post.

MacLeod also deals in recruiting bloggers to blog for the Macomb Daily. Although the blogs are the personal property of the writers, the newspaper gets to attach links to their website.

\section{Newsroom collaboration.}

Another duty that many of the editors spoke to as part of their daily jobs falls under the idea of intra-newsroom collaboration. This deals in coordinating different aspects of the newsroom together to create better-packaged content, reporting out about different aspects of the newsroom to the community, working across the borders of editorial/marketing departments, and training newsroom staff. Ogilvie often combines her connection to what else is happening in the newsroom and what content is being produced in her work reporting out about the newsroom to the community via a newsroom blog she curates called the Times Square blog. It is a place to highlight content and be more transparent about what's going on inside the newsroom. In terms of posting, it is a combination of posts meant to create conversation about current popular stories, to reflect what were the popular stories, and to put information out about the newsroom. For the last one, she collaborates with the marketing department to put out newsroom 
promotions or contests or introduce newsroom personalities. This work requires being connected and collaborating with other areas of the newsroom, a duty of the position that Plazas, Norton, and Velasquez also commented on. Part of Velasquez's original goals of the position was to increase visibility of reporters, which requires actually getting to know the reporters, what they are working on and what their needs are. For Norton, that means going to marketing events and talking up what reporters are working on:

I try to explain what the newsroom is working on for tie-ins and sales. I work with the marketing department on B2B marketing. I do a video each week promoting our content and I go on site. I'll take a videographer and go to a baseball stadium and say 'don’t miss our upcoming coverage.'

Plazas also works across the marketing/editorial border: "I talk to advertising folks frequently about what we're doing and whether our sponsors are interested in sponsoring a feature we are doing." While journalists traditionally have approached this line with caution if at all through editorial calendars or merely communicating what kind of content is coming up next for the newspaper. Plazas sees working with the marketing department as essential for newsrooms to move forward. "We have to be the number one champions of our work," Plazas said. "And we have to make sure we use all we can to get word of our work out there. I work with marketing to do that." He mentioned three different ways that he does this. Firstly, he tells them the three upcoming stories that are coming for the Sunday edition of the paper. They then send out promotion people to tens of thousands of people to let them know what's coming up. The second way is through writing content for electronic billboard promotions. The third way is through 
collaborating with marketing to provide prizes for contests Plazas runs to learn more about the community. While Plazas made it clear that editorial decisions are not influenced by marketing projects or needs, his position's duties represent an interest in linking the marketing department's skills at communicating with the audience with what the editorial department wants to communicate about, exposing the editorial department to a wealth of audience contact that was not available before.

The most common type of newsroom collaboration that editors spoke of was through newsroom training, which occurs both formally and informally. The most common type of training was social media training — teaching reporters how to utilize search on social media, how to post on social media, and how to brand themselves on social media. Norton said that while every reporter was required to have Facebook and Twitter when she began her position, she had to train them at different levels on how to use those platforms. She also helped craft policies and expectations that she would communicate to the staff on how to use those platforms. She also spoke of using monthly brown bag sessions to teach what new social media platforms, such as Storify or Instagram, could do for reporters. Velasquez also mentioned training other staff members on a certain style of posting to craft a unified voice across newsroom products even if there are multiple authors of the newsroom's profiles. Both Norton and Velasquez mentioned the information nature of the training too-sometimes it just means walking around the newsroom and asking reporters what they are working on, assessing if there could be a social or community component to it, and then working together to play that out. Plazas pointed out that after basic skills training, he also tries to bring some of his 
community engagement philosophy into reporters use of social media: "It's for the sake of finding and understanding our audiences. We're teaching them that it is not about followers or likes but it is about maximizing your storytelling skills." While other social media training may focus on the nuts-and-bolts of how to send a tweet or schedule a Facebook posts, his training deals more in how these tools can be used to better reflect audience interests' and reporters' needs to be connected with sources.

Abdul-Karim also mentioned training outside the social media sense, in which he will go along with reporters into the community to help them find sources in the black or Latino communities they might not normally tap into:

I think as a community engagement editor, I don't think my role is just in the community. I think it is providing hope to other reporters that I will help them and assist in any way I can in their endeavors in the community because of the relationship I have with the community. If you need me to go with you and be part of a conversation that would make you feel uncomfortable alone, I'll go with you.

This type of training deals with how to be more conversational in a community setting and less about simply finding community sources for a story the reporter is working on.

\section{Audience research.}

Audience research is a job duty that often overlaps with the four other duties but is for the purpose about researching and learning more about readers to better the news product. This usually happens in two ways - through analytics research (and 
communication with the newsroom about that research) and through talking with the community. Many of the techniques used in this overlap with this paper's later discussion of measurement and assessment of success. Audience research is not viewed as a job duty by most of the editors interviewed-most see it is as a byproduct of their other engagement endeavors. A few did speak of it outside the context of measurement and assessment, especially in regards to how to communicate their findings about the audience to other members of the newsroom. Plazas was the editor most focused on audience research as a separate duty from social media, outreach, submissions, or newsroom collaboration. His work deals in how to get deeper into digital audiences' needs and wants. He did anthropological research encouraged by IDEO (a design consultancy firm that identifies "new ways to serve and support people by uncovering needs, behaviors, and desires.”) on the habits of everyday people — not necessarily readers - in his Ft. Myers community in order to find passion topics and types of audience members to target content to. This meant finding people willing to open their lives to the newsroom and spending time with them. "We didn't ask them what they read, what their policies were. We asked them 'How do you live? What are your values? What is important to you? What's on your refrigerator? What's on your walls?"' Many of these interviews helped the newsroom to see trends in types of people that the newspaper could be serving in the community, which then informed the type of emphasis Plazas puts on different passion topics coverage. Plazas used an in-house marketing/research person to sort through a lot of data and industry research to see if their assumptions about their audience were verifiable. Changing content and emphasis based on these audience 
categories that Plazas helped create then helps Plazas see what is doing well and helps him measure the success of the newspaper's content.

In the past, the reporter used to say, 'I know what to put in the story because I know what the audience wants.' Now we actually listen and ask so we can actually tailor our news. We understand the community and why they live here. Asking people why they care about this place really helps us form everyday coverage. We're doing a lot more listening than we have done before and that data helps us.

Some of Plazas' audience research was done before there was any measurement of impact on daily stories to be done. Most often the audience research that community engagement journalists do is done while measuring and assessing their work and then reacting to those assessments in future engagement endeavors. That will be detailed in the next section. The information gleaned from those two types of research, however, also contributes to the editors' job duty of reporting this information to the newsroom, which almost every editor spoken with mentioned doing. Sometimes this means reporting on metrics for coverage engagement editors have nothing to do with. For Plazas, this meant speaking at morning news meetings with other editors about what was doing well on the news product's different platforms and why it was doing well. It also means crafting a monthly metrics report for publishers and the newspaper's leadership group showing what is doing well and what is not doing well. Many editors, such as Norton, found that though they were doing weekly analytics and audience reports and sending them to the newsroom, they just weren't getting read, so they stopped doing them. 
It wasn't getting opened a lot. You can slice a million different reports a million different ways but that doesn't get through to people in ways they can understand. So I try to keep my reports as general as possible, saying what is working and what we should repeat doing. We need to post at 9 o'clock, post with a picture, especially if it is involved with the military or traffic. I know what our passion topics are and I try to encourage people to stay on top of those.

Doing analytics reports or communicating audience research findings with the rest of the newsroom is rarely a job duty set out by editors' bosses, so communicating about findings is a somewhat undefined activity that often gets lost in deluge of many other newsroom reports or press releases. In other media, this audience research is often seen as a job duty of the marketing department. It seems that with these engagement editors, as marketing departments dwindle at newspapers, the job of audience research is being assigned to them because of the value they place on readers' wants and needs. Even if the ultimate end goal of learning about the reader is different for marketing and editorial departments.

These are five categories of job duty that almost every community engagement editor had some training or day-to-day duties associated with. What's important to note, however, is that each journalist had a totally different emphasis and angle to what the job meant to them. Even community engagement editors working for the same parent company had totally different job definitions and predominant roles. While one editor may be the king or queen or market research, another may barely have to time to do that among social media posting responsibilities. Some editors rarely work in the online realm 
and instead spend their time doing grassroots organizing. The position is varied from paper to paper. The three most common emphases, however, break down something like this:

1. Digital experimenters: Editors predominantly working with audiences in the digital world through social media, submissions, and digital outreach.

2. Community organizers: Editors predominantly working out in the community by designing community events and canvassing the community.

3. Engagement leader/coordinators: Engagement evangelists or gurus responsible for leading a new newsroom vision with a central care for the audience. They are focused on macro-goals and responsible for managing team members who do either digital experimentation or community organizing.

To reiterate, most engagement editors have skills in all five of the categories detailed above but often they specialize in one aspect of the job more than the others. All in all, the position of community engagement editor is an evolutionary and multi-faceted job. Norton put it best when she said:

I think the beauty of the position and what attracted me to it is the fluidness of it. We don't know the question marks, so let's play, let's experiment, let's see how this works because it's the Wild West. That's where I like to be. To have someone map out my day and have it be the same everyday would be a failure to what this position is. It's very exploratory, it's very experimental. That's what you're supposed to be, you're supposed to be a student of the media. I'm enjoying figuring things out as I go. 
Most editors noted that the position is rooted in experimentation and often requires a multitasking mentality in order to do the job. In fact, it is part of what attracted most of them to the position. After talking with these editors, it seems that sometimes there is so much going, so many different roles that an engagement editor fills, that it becomes hard for the editor to keep track of everything they are doing. This is part of the problem of assessment, which will be detailed in the next section.

\section{Assessing success and the impact on editors' decision-making}

Engagement editors assess their success in many different ways - mostly due to the multifarious nature of their job duties. This thesis will look at their ways of assessment through two lenses by looking at how those measurements are done qualitatively and quantitatively and how different types of measurement are dictated by job duty, which will answer RQ 2A. Then, this section will address how decisions are made based on those assessments and measurements, which will answer RQ 2B. Finally this section will look at some of the barriers in place that help engagement editors resist assessment and decision-making in their jobs, which will help illuminate why engagement editors don't place high priority on measurement and its influence on decision making and will give a jumping off point for a discussion on how to improve the engagement editor position. 


\section{Assessing the success of different job duties}

\section{Assessing social media.}

Quantitatively, the number one way that these journalists assessed their social media work's success was through Facebook Insights, Facebook's branded tool for analyzing who visits your page. Likes and followers to a page (and, in some cases, tracking who unliked the page) was most often mentioned as the easiest number to track, though the superficiality of the number's importance was also noted. Shares were also noted as highly important because they denoted that people cared enough about the content to share within their own network. Number of post comments were also mentioned but not as often as sheer number of likes and shares. The same assessments also applied to Twitter and Google+. Google Analytics numbers for pageviews, referrals, and click-through rates were also mentioned as important assessment tools, but the numbered benchmarks associated with that were often made up or from personal goals not based on anything. Other quantitative measurements included standing in Google search engine rankings and number of comments. Overall, qualitative measurements of social media success were rather superficially created and hard to make decisions based off of because of the superficial nature of them. Oftentimes, the most helpful quantitative assessments were done comparatively. Editors mentioned both comparing their current performance to previous performance before they started their position and comparing their performance to other similar media outlets. Velasquez said she often solely asked the question, "Are these products growing faster now than before I got here? It's growth over time and quality growth too." Plazas echoed this sentiment of improvement as a 
basic measure. Measuring one's work against other social media counterparts was not uncommon because Facebook and Twitter followers are publicly accessible popularity benchmarks. Norton asked the question, "Are we keeping up with other sites as far as how we're presenting ourselves?" Ogilvie also mentioned looking at competitors in her area in terms of Facebook likes and Twitter followers. Velasquez turned to media colleagues for feedback. “There's one guy I work closely with and he's got a good idea of what other media outlets' numbers are like," Velasquez said. MacLeod measures her work against the work of other newspapers under her parent company, Digital First Media. "Overall, I think Macomb Daily is twelfth or tenth in terms of webviews on the website," MacLeod said. "We're in the upper third."

There were also qualitative measures of success mentioned by engagement editors. There was a heavy emphasis put on the quality-over-quantity aspect of comments on social media and the news product's website that reflected a "healthy conversation" measurement. "I would say if there's a lot of chatter back-and-forth, that's a successful day," Norton said. "If no one is talking about what we're reporting on, that's not a good day." Other measurements included assessing the degree of helpfulness of social media posts and how many inter-reader connections were being made in comments on social media. "It wasn't number as far as how popular it was, it was how people were reporting and helping each other," Ogilvie said of her social media work during a windstorm. The type of people that conversations were occurring with online also was a way of measuring social media efforts' success - Velasquez mentioned that a retweet by President Obama would be seen as a great success because of the breadth his following 
and standing in the world. Surprisingly too, several editors mentioned the idea of measuring the "immediacy in popularity" which might be equated to viral-ness of content posted to social media.

Assessing ones' social media endeavors were done quantitatively through follower measurement and comparative analysis of improvement over time and in relation to other news outlets. Qualitative measurements were done through tracking of conversation quality, which meant helpfulness, immediacy, and celebrity of responses.

\section{Assessing Community outreach.}

Measurement and assessment of community outreach work takes on a bit more a qualitative bent because there are simply less numbers to measure in face-to-face interactions. While some editors mentioned event attendance numbers as measures of success, they are hard to compare because each editor has different expectations, different communities, and different space hosting capabilities. For example, Norton spoke of what she saw as three highly successful social media events where there were 100 to 150 people in attendance. Compared to event attendance numbers Abdul-Karim reported however, 200-500 attendees, those numbers seem small. The best way to measure event attendance numbers is to do it through comparative analysis of past events, as Parris did with three community cafes he held. The first two, he said, were smash hits because of the amount of people in attendance and what was learned from the events. The third was barely attended because of an off-the-beaten-path location, which he considered unsuccessful. But overall, 2/3 he did consider successful so he saw the cafes as overall successful. Revenue from events was the only other quantitative measure mentioned, 
though rarely put in use, because marketing departments usually handle the money side of the events.

Qualitatively, editors often measured their feeling of leaving a good impression or changing minds in the community about their news product. Several editors said that they felt if they had a few good quality conversations with community members that led them to contribute or think differently of the paper that was more successful than simply talking to many people. Some editors looked for a gut feel of positive feedback from multiple avenues. Abdul-Karim explained thing by saying, "Because I'm connected in the community, I get feedback from folks in the comments section, or they'll email me, or call me." While he does not log all of this feedback, he forms a gut feeling of if an event he put on went well by assessing the majority of comments he receives. He also puts out event questionnaires, which help him take the pulse of the crowd and if they thought the event was good or bad. Brewer mentioned measuring community outreach success by seeing how many different places he could go and the diversity of those places. He also mentioned being interested in how much new information he could garner - if he "learned something new" he considered his time in the community a success. This success measurement stood apart from interpretation as a business success and Brewer found merit simply from the journalistic value of reaching out into the community and community building. Is this defensible as time well spent? Brewer did not think he had yet to defend it because his supervisors were not asking for that kind of justification yet.

\section{Assessing reporting/submissions.}


Quantitative assessment of reporting and submissions work comes down to two things in these editors' eyes: number of participants and pageviews. Using Google Analytics, many engagement editors looked at how many people read stories with a community component to them. Parris offered an example: "In the 'Cost of Coming Out' stories, out of the top five, three were community testimonials." He considered the engagement posts' contribution to total pageviews as a success. Editors also looked at the placement of engagement-fueled coverage in comparison to traditionally reported coverage. A couple of editors mentioned that if their work was up with traditional reporting in terms of pageviews (perceived as popularity), they knew they were doing something right. Number of participants is the other big measure in reporting and submissions. As Parris said, "Anytime you can get anyone to participate in what you're doing, that's a success." Qualitatively, reporting and submissions success was assessed by looking at the diversity of people represented in the paper and the quality of submissions and comments. If there were many responses to a question posed by the newsroom but all of a short and unhelpful nature, editors viewed that as unsuccessful. One long, well thought-out response however was seen as a success.

\section{Assessing newsroom collaboration.}

Editors did not speak at length about their assessment of newsroom collaboration efforts. What they did mention, however, was of a combined qualitative-quantitative nature in regards to staff training. They often looked at and recorded how many reporters were adopting their social media training techniques. Qualitatively, they looked to see if 
the quality of their social media use escalated and if they were holding conversations with readers in their own right without newsroom prompting.

Overall, quantitative measurements of different job duties appeared to be rather superficial in nature - although numbers were measured, there is little reasoning behind why reaching a certain number matters over another. The most helpful qualitative measures of success were done comparatively in relation to previous work or to other newsrooms' work. Qualitative measurements of different job duties seems to be rather subjective and hard to replicate as it is usually based on interpreted feelings of goodwill or living out of journalistic goals such as increasing the diversity of the paper. Although editors were committed (to varying degrees) to continue tracking these measurements, their enthusiasm for doing so seemed to wane because of a lack of a vocalized end point. This made decision-making on what to keep doing and what to change in their engagement journalism difficult and could be one of the reasons vocalizing their decision-making process was so hard, as the next section explicates.

\section{How measurement and assessment influence engagement editors' decisions}

Engagement editors do collect and take measure of their work both quantitative and qualitatively. Although they have many modes of collection and, in some cases, dissemination of those measurements to newsroom staff, what is most interesting about talking to these editors about measurement is how they think about what they do with these assessments and measurements once they have them. The decision-making process for how they move forward with their work given their reflection and data on what 
they've already done is more subtle and hard to vocalize than simple $\mathrm{x}+\mathrm{y}=\mathrm{z}$ formulas on what to keep doing, what to stop doing, and what to evolve. In fact, few editors were able to vocalize their decision-making habits after data collection.

There are day-to-day micro-decisions that come to be based on previous feedback and promote a change in behavior on the part of the engagement editor and there are macro-level decisions to come be based on observation over time and utilitarian assessment of seen value vs. time input. Both are guided by the idea that an editor has gut instincts that he or she validates through data collection. Abdul-Karim illustrates simple day-to-day decision-making that happens when he gets feedback from an event through a questionnaire and uses that information to alter or tweak how he puts on the next one. He takes qualitative and quantitative data gleaned from the audience about his work and later uses it to change his behavior at community forums. His positivity and reassurance about making decisions based on this data may be rooted in the fact he is mostly working with qualitative feedback from humans. Norton, on the other hand, represents the hesitancy most other editors vocalized about making decisions based off of quantitative data alone. “There's some days when the reporting is really good, but it's not something you can talk about," Norton said. "There's not much to say, it is what it is. The future might be: do we run the story if it isn't a talker? Or do we feel obligated to run the story because it is good to the community?" Although she realizes that data collection and measurement is importance, there is some reluctance to make decisions based on numbers and popularity alone. She recognizes that a story's popularity is key with readers, but that there may be a journalistic obligation to run stories that aren't always popular. Short-term decisions 
made based on data collection is considered hard because there isn't enough time to synthesize all the reasons something did well or did not do well. Editors are uncomfortable making decisions without all different types of measurement (qualitative, quantitative, comparative) available to them.

The more common way that editors were able to vocalize their decision-making process was in the long-term, by describing "gut instincts" they have and how rather than ignoring those feelings, they validate or invalidate their decisions through data collection. This allows editors to take qualitative and quantitative measurements of success and eventually tie those numbers to types of content, timing of content, the way of presenting content to make decisions about how they do those things in the future. Many of the editors this study spoke to had not yet gotten to this point in their job-they were still experimenting with the position to cultivate a gut feel. For editors who felt they had a gut feeling from working in their position long enough (in most cases, over a year and closer to two years or more), data collection became a way to verify that what they thought was working actually was working. "There's a feel but I definitely use numbers too," Velasquez said.

The success of a post on Facebook, for example, can be pretty predictable. I shouldn't say that's definite but knowing the Buffalo audience, I know that certain topics and images will get them revved up. That's proven by numbers of shares, numbers of likes, numbers of interactions (responses) with the post. I put certain content on Facebook that I might not put on Twitter or put emphasis 
somewhere else and that's because there are different audiences on different social networks.

Velasquez shows that she obtained, over time, a feeling for what her audience wanted through her connection with them. Then, she looked to prove that instinct through data. Ogilvie echoed the same sort of process:

What informs my choices is observing how people react to things over time and looking at data too, which validates instincts. I feel like I'm always adjusting what we do based on response. Every day, every week, I'm constantly reprioritizing. Let's not get hung up on how we've always done it.

Though few other editors were able to vocalize this hypothesis/data collection technique for decision-making, the ones that were able to spoke about a utilitarian assessment of value to the audience/newsroom vs. time input, which leads to replication of successful content and honing of how and engagement editor does his or her job. Plazas put it simply: "If we know something is working, we definitely want to replicate it as best we can." As Ogilvie put it about a decision she made to end a project she was working on, "It was fun but time consuming. It was hard to do.... I just wasn't seeing the traffic that justified the time." Ogilvie experimented with something new for several weeks, looked at reader numbers over time, and analyzed how much time she was putting into her work before making the decision to ultimately axe the project. Velasquez talked of a similar process she's in the middle of for determining what's useful for the newsroom to do. I have to determine if we are using live blogs and videos appropriately. And if they're worth the manpower and time they take to make. There's not a price tag or 
something, but if four people are dedicated to this video project for two hours and it only gets 100 pageviews, is it worth it?

It appears that increased contact and interest in the audience does not make engagement editors more easily capable of making short-term gatekeeping decisions for their coverage. In the long-term, however, the formation of editors' gut instincts from reader interaction makes them able to check their assumptions about what readers want and need with measurements they accrue of what readers actually do. This makes the engagement editor able to cut out types of engagement techniques or coverage that they do, and thus determines what makes it into the news product online or in print.

\section{Resistance to assessment and using assessment for decision-making}

Although editors were able to explain different ways they measured and assessed the success of their work, and were often able to vocalize how those measurements could be used to influence their decisions, there seemed to be a disconnect between the two in the short term. In the long-term, editors put forth extreme hesitancy in making commitments to how they make decisions about if they continued doing what they do. What follows are the reasons vocalized by editors as barriers or restraints to using qualitative and quantitative success assessments to inform decision making in their jobs.

\section{Many different job roles lead to time constraints.}

On the most basic level, having a job that is all about multi-tasking and experimentation, leaves little time for reflection and assessment. The constant news cycle and nature of social media also contributed to this feeling of having little time, or always 
being distracted by something to sit down and assess prior work. "I haven't had time to invest in strategy and making my work consistent," Ogilvie said. "I don't feel we ignore the analytical information we get. It's always in the back of my mind. My problem is that we have too much content. We're churning out so much, it's hard to keep up."

\section{Many different tools for many different jobs to measure.}

Each different job duty an engagement editor takes on requires the use of different tools, applications, and approaches for measurement. While in-person outreach may depend more on spoken, qualitative feedback, social media work may be more suited

toward measurement in quantitative data. Assessing each segment of what an engagement editor does in a different way, when that duty is not even the majority of your work is taxing. Likewise, as the engagement editor position evolves so do the ways of measuring the engagement editor's work. As Velasquez put it:

There's always a way to measure success. I've gone through this journalism thing thinking there's always going to be a new way to measure success. So I keep measuring in every way possible to have as much info about our progress as possible. It is up to whoever makes decisions to determine if we are indeed flourishing or not.

Because there are so many different ways to measure success, there seems to be little room in day-to-day activities to also determine what that success means.

\section{Journalistic autonomy.}

Another reason some editors were not able to vocalize their process seemed to be from air of journalistic autonomy - of protecting one's own data so it could not be used 
against them in hiring decisions or a bad reflection on job performance. Ogilvie summarized it best when she said:

I don't have those hard and fast milestones. It makes people uncomfortable when you talk about that. It's sort of my personal thing, as the keeper of the blog, and I have all these options and directions I could go. Analytics are just one part to help me make those decisions. I don't present those numbers to any one and no one asks about it. It's for my own knowledge.

\section{Unpredictability of community.}

Sometimes people just don't want to engage around a topic or job duty that engagement editors take on. Sometimes there's just no logical explanation - it may be sunny outside and people aren't online, or some simple twist of fate kept people from showing up to an event. The unpredictability of the community's consumption whims made editors very hesitant to depend on their feedback for making decisions. Parris spoke to this when he talked about measuring success based on how many submissions he gets from readers: "It's always that we don't know how many stories we're going to be able to get. We don't know what new topics will resonate with the community right away. We have to try first."

\section{Lack of comparative data.}

One of the things that makes measuring and decision-making based on comparative data hard is the sheer lack of that data that is available publicly. While Twitter and Facebook followers are public knowledge of newsrooms with those pages, that is really the only comparable data editors have to go on to assess how well their 
newsroom is doing in comparison. Though most editors agreed that followers and likes are superficial benchmarks, they used them because it was the only thing that could compare them to other markets. That's not for lack of trying. "There's a couple of websites where it is not completely reliable, where you can see a rough estimate of page views for websites that have not made that information private," Velasquez. "We compare ourselves to similar markets and we see where we stand."

\section{Lack of faith in simple quantitative formulas.}

Most editors get hung up on decision-making based on assessments when they think of assessments purely quantitatively. They still find qualitative assessment essential and solely data-driven decisions as superficial instead of looking at assessment as dually qualitative and quantitative and then make decisions based on that. "[The company] gave us a benchmark formula for the company that they're now questioning," Norton said. "Very X or Y, this or that. And it didn't make sense. You can use the formula and get a number and prove almost anything that you want." Parris also rejected the idea of purely quantitative decision-making:

I've lived in data-driven decision making. I've been there. I think when you're doing stuff like this, though, its half metrics and half gut. The metrics aren't going to tell the story always. And metrics can be off or out of context. Your gut's not always going to be right. Metrics can put you on a road but I don't think you need to make every community engagement decision driven by that data. Sometimes people get too wrapped up in it and that clouds the emotional story you could be telling. 


\section{Experimentation culture leads to focus on constant improvement, not end goals.}

Almost every editor interviewed mentioned that one of the biggest differences in their job from other jobs in the newsroom was the job's emphasis on experimentation and evolution. Often, this culture of "try new things" just to try them seemed to lead to a focus not on an end goal (because that would be restrictive) but rather a focus on constant improvement over time. "Right now we are just experimenting with lots of things," Parris said. "Engagement is pretty new to this company. When some things become consistent, you can apply benchmarks." Connor echoed something very similar. Velasquez spoke to the idea that improvement is often viewed with awe after periods of stagnation in numbers or no one measuring them. "For us, there's nowhere to go but up," Velasquez said.

If things go down, they should fire me immediately. There was so little structure before me that absolutely our numbers should be going up with me. If it levels off, that's okay. Especially with social media outlets, I anticipate leveling off or dipping slightly over time because the algorithm structures change. Other structures will die off. I just need to stay on top of where traffic is going, where our audiences are moving to, so we can make the most of that.

Brewer emphasized that having a lack of milestones to hit was helpful in his year of experimentation with the mobile media lab because there was less pressure to perform on a deadline. He did emphasize that specific benchmarks would be created now, in the year after experimentation. MacLeod spoke to the idea that showing improvement is enough during the experimentation phase and that often had to do with supervision from higher- 
up. "We haven't set concrete goals, its all about moving forward, whatever far we get now," MacLeod said. "The company has not set any specific metrics, right now we're just trying to monitor and improve." Specific metric creation seems to be seen as a job of bosses or other companies as a whole, not to be created by the editors themselves.

\section{Lack of guidance from supervising editors.}

MacLeod touched on an idea that was actually the most prolific excuse for not having more exact measurements or decision-making techniques in the engagement editor position - in most cases, editors were waiting on guidance from editors on what they wanted to see or look for. This lack of guidance either made editors feel really antsy about the justification for their position or made them feel secure in their ability to experiment. MacLeod was actually one of the editors who vocalized security:

Right now, anything is viewed as positive. So much of this is revolutionary that I think my supervisor is a cheerleader, seeing how far we can get. It is a win-win situation for me because I don't have any concrete numbers. I just need to keep producing.

Parris, likewise, felt positive about the lack of guidance of requirements of proving worth of his activities:

At this point I'm not worried about it. I think I run a good ship here and I think I could make a case for what certain things are most important in terms of measurement. I'm not worried about it and I think my bosses have enough confidence in me to make the right decision. 
A lack of insider knowledge of what an engagement editor does was often seen as the culprit for why little supervision or reporting of measurement was asked of engagement editors from bosses. "We report numbers up the chain to our bosses but there's no official goal," Beck said. "We need to justify our existence but we don't have a rubric or framework. It's more set up in the way that we talk about how things are going narratively."

Both Connor and Brewer mentioned that at this point, a little more supervision and guidance in what goals and benchmarks they should be aiming for would helpful from their bosses. "I'll tell my bosses what I'm doing, but there's not follow-up to it," Brewer said. "It'd be nice to have a more formal process at this point. For a while it's nice to have freedom but eventually you want to know what you're doing is okay, or that you're making progress." Connor expressed a little more confusion and fear about the lack of supervision, which is actually leading to her assessment of if the job is right for her. Norton spoke to the idea that a lack of supervisory goals and measurement requirements not only hurt her ability but to take stock of what she's doing well but that it is also an issue of workplace respect:

I guess there are other companies or people or positions that are building reports in a much more consistent way and that's either because their management respects that and understands that but I'm not in a position where that happens. That both helps and hurts me. There's a lot of trust in me to do it right. A lot of people in my position can either evolve or grow in such vastly different speeds and ways because of buy-in or lack of buy-in. 
Although editors measure what they do in many different ways, these barriers seems to be getting in the way of their creation of a formal decision-making process. While some editors exhibited an ability to combine qualitative and quantitative data to check their gut instincts and make decisions moving forward, it appears that more editors would be able to formalize their decisions by solving the problems listed above.

\section{Balancing the assessment of journalistic and economic capital}

Naturally, when talking about job duties and goals and measuring performance of those duties and achievement of goals, engagement editors began to reflect upon the worth of their job. This was probed further through questioning about how they balance the assessment of journalistic principles (ethics and ideas of community service) and business concerns. Although editors were able to vocalize the measurement of what they do, and some were able to apply that to decision-making, engagement journalists interviewed on the whole unable to connect the reasoning behind why better decisionmaking was necessary for the newsroom's business. They were much better able to vocalize why what they were doing was valuable on journalistic principles level. For most editors, this left the surface assumption that good journalistic principles practices automatically led to good business for the paper. For the rest, it simply meant that business concerns rarely ever even crossed their minds.

There are three basic levels of understanding of the balance between journalistic principles and values and the business side of a community engagement editor's position, which all operate on a varying levels simplistic understanding of how product makes 
money. At the most basic level, the journalist considers the business side of things to be someone else's job typically in the marketing, circulation, or advertising departments. Every journalist spoken with had this understanding of 'I'll do my thing, and they'll do theirs." Several only thought this far about the business aspect of their work, in what seemed like an attempt to gird themselves from perceived bias of business concerns. As Connor put it, "The business side is above me. I try my best to make sure things I do are done well and hopefully that increases traffic and visibility. I guess the connection is not clear to me. I'm not necessarily included in those business conversations." Martin Beck also echoed the idea that business concerns are something that stay completely separate from his work. "There is a promotional aspect to social media, but our highest priority is to present news and features," Beck said.

That's number one for us and part of being responsive to the audience is wrapped into this - we want to share the news, to make sure it is accurate and timely and complete as possible. The business, we hope, continues to be a business. Our role is to tell readers stories that we do and respond to them about those stories. We hope more people will have a relationship with us because of this. We trust that our business side will figure out ways to take advantage of those people to have the business grow and be profitable.

The next level of understanding still holds that journalistic work and business concerns should be held separate but also adamantly holds on to the "if you build it, they will come" mentality. These journalists believe that the better they make their content-and content is made journalistically better by having a more engaged community reflected in 
the news product - that audiences will recognize and reflect that through subscriptions. As Ogilvie said:

I've always been audience-focused. No matter what section I'm in, I'm thinking about the reader and how the reader would see this story. What is the most useful? How could I best teach this? If you're pleasing your audience, that's a good thing for business. That's how I've seen it. I don't have direct correlations with how much money I'm bringing in. Its hard to qualify feelings people have-feelings of goodwill or not—or what they value your work for.

Ogilvie also added, “The best journalism that we do is based on the relationships we build with the community," which seems to point to a reliance on journalistic values to assess the overall importance of an engagement position and that there is little business thinking that goes into signing up to be an engagement editor. Velasquez also represented a relief at working a place where journalistic values were held higher than business values, because she had previously worked at a place that was more concerned with marketing. "I don't want anything to do with advertising or marketing," Velasquez said. I'm going to put out what the audience needs. I'm going to publicize our content. It's almost $100 \%$ journalistically motivated. Providing info to audience. I am concerned about our pay wall. I have to make sure there is so much content that is interesting that the audience has to read it and they will run out of free views. I want Buffalo News to be so valuable to their lives that they can't help but sign up for a subscription to this info I'm pumping out there. A lot of it is really good and enticing, well-written and researched. I hope that will push them to sign up for a 
subscription. But that is more of a secondary goal. My primary goal is journalistic.

Velasquez reiterates that there is an understanding of the need to be financially viable as a business but also exhibits the fear that business concerns have and could taint a focus on providing better information to the community (a traditionally held journalistic value). By labeling journalistic values as a primary concern and business concerns as a secondary concern, she summarizes how most engagement journalists felt about how they balances business and journalistic values - some just thought a little more about the business values than others. Parris exhibited an intense loyalty to readers over the newspaper itself, which almost completely removed concern about the business side of his work from his mind. "Readers will go wherever they get the best information from," Parris said. "I think the reader goes for the best experience. If that's PennLive.com, that's great. If someone comes around and does it better than us, then readers should go there. We need to do the better job." This shows the intense assumption that was adopted by most of the journalists spoken with: it is the responsibility of the newspaper to make content great and that will respond in readers taking notice of this great content and becoming more loyal and supportive of the paper. None of the editors interviewed, however, were able to vocalize that readers ever intimated being able to tell the difference from previous un-engaged work to engaged content.

Two editors did come close to this understanding this concept, though, and they represent the most complicated understanding of how a newspaper's content and business strategies combine. The understanding is still rather simplistic, but both Brewer and 
Abdul-Karim were able to explain how they though their work resulted in business benefit directly. Abdul-Karim thought that an uptick in revenue would be a natural progression out of his work in the community, because he saw himself making connections with people the paper had previously ignored - the black and Latino community of New Haven.

You know $90 \%$ of the folks that I see in the newsroom are white. So I think as community engagement editor, it is natural when you're in the field working and people begin to trust you and being to actually see themselves in the paper, they are more likely to advertise their business in the paper. Whereas before, why are you even reading the newspaper, let alone advertising in it? I've come in and begun to build trust within the community. It's going to take time for other minority businesses to advertise because that trust factor has not been there. I come in to build a bridge, and I think down the road folks will begin to advertise in the paper.

While this progression represents a very traditional revenue model for newspapers, it was as close as any of the editors got to making a direct connection to the business side of the newspaper. Abdul-Karim also clarified, however, that he doesn't "go into a situation thinking, "increase revenue." He sees it more as a natural progression over time and was not yet able to prove that his connections had in fact raised advertising from the minority community in the newspaper. Brewer also was able to vocalize the direct connection from his work to revenue for the newspaper. Brewer said: 
We typically don't fret about the business value of the work. The money part, no. The idea always is, the better the content, the more readers, the more readers, the greater circulation, the greater the circulation, the more you charge for advertising. That ends at a certain point. It's not a very direct relationship. I try not to focus on it too much.

His point is valid: in addition to all the other duties a community engagement editor has there is not much time to concentrate on an indirect business relationship. Norton, however, explained a little bit about why this lack of interest in understanding the connection between journalistic success and business success may be dangerous to engagement editors: job security. "I know that our company no doubt believes that engagement and social media are huge tools and are a part of our mission," Norton said. "But, even people at our corporate offices have revenue pressures and demands. Sometimes that gets in the way of that mission." If engagement editors are only able to vocalize the journalistic value, the mission of their work, and unable to explain how what they do leads directly to revenue to bosses in charge of hiring and firing, that may cause problems with job longevity, especially in a position that is so untraditional and does not provide as much tangible content as a traditional reporter might for the newspaper. All in all, journalistic values are easy to identify for these journalists and they are easy to tell if they're being fulfilled.

When asked about what separates good community engagement from bad community engagement, not one single editor mentioned business concerns or business viability as something that made or broke community engagement. There was not even a 
mention of analytics measurement as something that determined engagement to be good or bad. Every single thing they said made community engagement good or bad dealt in journalistic values. Some of the values espoused were accessibility and urgency of response, authenticity and deep relationships, showing credibility in the community, being out in the community, accuracy, starting conversations in the community. As Abdul-Karim put it:

I think the most effective way to engage the community is to be out in the community. Show people you are trusting and credible. And once you build up that credibility, you gain a respect and trust that people will share things with you. You get powerful stories from being in the community talking to people. That creation of more powerful stories is the sign these journalists want and need to see to know they are doing their jobs well. Business concerns don't trouble that because they believe that readers recognize the difference in quality their position brings to the newspaper. 


\section{CHAPTER SEVEN: DISCUSSION}

This research set out to answer three questions about the position of community engagement editors at online newspapers. Firstly, it sought to answer the questions of what the conceptualization and reasoning behind the position of community engagement editors at online newspapers was and what daily activities and goals of those journalists were. Secondly, it sought to find out how community engagement editors assess and measure the success of their journalism and how those assessments influenced gatekeeping decisions. Thirdly, it sought to assess how engagement editors thought of their journalistic and economic capital and how that intertwined with traditional journalistic principles.

To answer the first question, this research found that the job title of community engagement editor means a variety of different things to different publications. The paper may hire a community engagement editor to manage digital experimentation with the community (which includes social media and work with alternative story telling), to actively outreach into the community (which includes event organizing and being the public face of the newspaper), or to be an engagement leader/coordinator (which includes managing a team that takes on the aforementioned roles and spread idea of engagement to the rest of the newsroom). These are the three types of emphases that community engagement editors have, though they all have skills in social media, community outreach, reporting/submissions contributions, newsroom collaboration, and audience research. The single most defining traits of the community engagement editor is that their 
job duties are multifarious and constantly evolving. Goals of the position were rarely articulated as easy-to-reach benchmarks but rather as lofty journalistic ideas without articulated end-points. Goals articulated such as increasing the newspaper's visibility within the community or increasing the number of social media followers often left a divide between if editors were striving to reach journalistic or economic ideals and thus were hard to measure with no clear place to start.

This discussion bled into the answer to the second question, which showed that engagement editors $d o$ measure and assess their work both qualitatively and quantitatively for a variety of their job duties but often have a hard time translating those measurements into actionable decisions on a day-to-day basis. Often, longer-term decisions about coverage and duties are easier to make given the use of utilitarian assessment of journalistic and business added value vs. amount of time put in by the person doing the journalism. However, engagement journalists are skeptical of committing to cut-and-dry calculations of "here's what we should keep doing" and "here's what we should stop doing" based on seven barriers, which are: many different job roles leads to time constraints, many different tools measuring many different jobs, journalistic autonomy, unpredictability of the community, lack of comparative data, lack of faith in quantitative formulas, the culture of experimentation embedded in the position leads to a focus on improvement and not end goals, and a lack of guidance from supervising editor. These barriers seem to be hindering traditional gatekeeping processes for short-term decision-making about engagement work to continue, stop, or evolve. 
The answer to the third question showed that engagement journalists have a very simplistic understanding of the balance between their journalistic and economic capital. On the whole, engagement journalists forcibly removed themselves from learning about their contribution to the business side of their work because they believed it would bias them. If they did take interest in how their work led to business value it was in an indirect and secondary way. Several journalists were able to identify that they thought their engagement journalism created better content, which, in turn, would bring more readers to the newspaper. Fewer journalists were able to articulate that that might mean an increase in circulation/subscriptions and advertising. As assessment of what they thought made good and bad community engagement proved this idea-not one of the ten editors interviewed mentioned business viability as a sign of success of their work, they only listed their additions to bettering journalism and journalistic principles for the newsroom through their work. No editors mentioned that an understanding of analytics or reporting on analytics contributed to successful community engagement, which would probably be the closest thing to recognizing their work influenced the newspaper's success.

This research is important because it defines, in its many different iterations, what a community engagement editor is, which has not previously been done in academic research. It sets out a path for which online newspapers that don't currently have the position could create one by defining job duties and also points out some of the challenges current engagement editors have that could be circumvented by future supervising editors. Secondly, this research is important because it offers standardized ways of measuring and assessing community engagement endeavor, which has not been 
set out before. Although some of the measures are vague, this research shows that pinpointed benchmarks vary publication-to-publication and position to position and may never be something crafted for the position of community engagement editor as a whole. It also points out the barriers to measurement and gatekeeping decision-making that a savvy engagement editor could attempt to solve before embarking on doing community engagement work. Thirdly, this research shows that although these community engagement editors may have greater communication and connection with the community they serve, this does not impact the way they view the journalistic and business value divide in the industry. The engagement journalists interviewed still represented a tradition of separating newsroom content and business considerations that place them solidly on the side of editorial, although they do make some strides to understand how the business end of things works. Overall, this research is important because it represents the next step in the flow of information about the professionalization of community engagement values in journalism, which have flowed from principles of public journalism.

This research is also important because of its contribution to the flow of information about current theories and previous literature about journalism. In terms of the conception of the community engagement editor position, this paper found that these journalists also saw engagement as valuable as Vujnovic et al. (2010) did in her interview 60 journalists about community engagement, though they weren't able to vocalize the value in such strictly monetary terms. They were more able to focus on the achievement of higher journalistic goals that Nip (2006) pointed out. This research reaffirms the duality of 
assessing success monetarily and in a values-based way. This study found that there was more of an emphasis on principle benefit than vocalization of financial benefit by community engagement editors. Mayer (2011) found that journalists practicing community engagement journalism could not vocalize concrete evidence of the success of their efforts. This was not the case with the community engagement journalists - while they were able to come up with a myriad of ways how their work was successful both quantitatively and qualitatively, they had trouble vocalizing why that success would matter to their bosses. Mayer (2011) wrote that she thought the days of not having to account for resources would not last. It appears, through this research that as of 2013, supervising editors still aren't asking for evidence of success, even though editors are taking stock of their successes and failures in some ways. This lack of guidance by supervising editors actually seems to the biggest barrier to making decisions based on measurements and, for some of the editors interviewed, bosses asking for evidence of success would actually be welcomed. This raises the question, have supervising editors doomed the position of community engagement editor by allowing too much experimentation and not requiring accountability? If supervising editors don't start asking for more evidence of success, engagement editors might stop constantly recording any and all types of information because it is simply too time consuming amidst all their other job duties.

Buttry (2012) defined a community engagement editor as someone who took on the roles of managing social media accounts for the newsroom, coaching newsroom staff, leading efforts to open the newsroom to the community, recruit local blogging network, 
lead newsroom efforts at curating and crowdsourcing, establish community partnerships, and trying out new social tools. This study found that, yes, community engagement editors do dabble in all of these roles and more. This study also compounded that information with the idea that community engagement editors often emphasis in a certain area of community engagement work depending on where they work.

Original definitions of public journalism often took on a democratic tone, and highly emphasized civic action and participation in a democracy as end goals of engaging citizens in journalism. This study has found that this emphasis on improving democracy is all but gone in its professional outgrowth to community engagement editor. The emphasis on community engagement journalism has now turned more to the idea of fostering the community through improving the readers' access to information and inclusion in a community totem - the local newspaper. Some democratic themes still appeared in what the editors talked about such as increasing the number of voices represented in the paper or the diversity of those voices represented, but were not directly tied to an idea of improving democracy. Previous research by Lambeth et al. (1998) also noted that criticism of public journalism because of a lack of concrete definition of the movement. This is a problem that persists into the role of community engagement editor. The many different definitions of what public journalism meant to do can be seen reflected in the multifarious and varying job duties of the community engagement editor today. The varying job descriptions from publication to publication can be seen as a barrier to creating metrics and measurements of success in those efforts across the career because every position has a slightly different emphasis. Lambeth et al. (1998) also 
pointed out that, "Public journalism's failure to show immediate economic benefits could prove a major disadvantage. ...Because there is more than one way to do public journalism, it will be important to know what ways to do most at the least cost." It seems that engagement editors are still not able to vocalize a direct correlation between their efforts and monetary gain for the newsrooms they work for, and in fact, they shy away even from the attempt. If this assessment still holds true, as Norton pointed out, not being able to qualify benefit monetarily could spell job insecurity of engagement journalists.

Shoemaker and Vos (2009) defined gatekeeping as decisions that occur when a communication worker forms information about an event into a message. Donohue et al. (1985) wrote that different forces then influence how individual gatekeepers shape, display, time, withhold information, or repeat messages in a gatekeeping cycle. This also happens in decision-making with community engagement journalists. This study showed, however, that they hold audience feedback in high priority when making decisions than other personal factors - with time input to activities as a close second priority. Shoemaker and Vos (2009) also pointed out that journalists traditionally have a secondhand idea of what the audience desires of the media and that journalists rarely accept market research on their subjects. This is definitely less the case with community engagement journalists - in fact, part of their job description is actually doing that "market research" themselves. These journalists do have increased community relations, sometimes in very blatant ways when they ask community members what they want to see in the newspaper. Other times, that feedback is more subtle and compounded with readership data to make decisions based on what audiences want and need. 
This subtlety is reflected in how these editors' decision-making processes result in content decisions. Often the gatekeeping process becomes more informal - an editors' listening and community building within the community results in the passing on of a story idea that results in content written by another journalist. In other cases, the editor acts as a "gatewatcher" that Bruns (2009) refers to in that he or she acts as moderator, selector, or emphasizer of content rather than the creator. This happens especially with the engagement editor's social media role in the newsroom or, in the case of someone like MacLeod, when choosing contributors who have autonomy in content creation but the news product has license to share, link to, or use. In some cases, the engagement editor does act as a traditional gatekeeper in that they do interviews or act as the liaison to sharing another community member's message. The variety and conflict between these gatekeeping roles in content creation may act as a model for how gatekeeping in journalism is evolving today. Starkman (2011) wrote about the future of news becoming a strictly network-driven series of interactions between user and journalist, which was a prediction that would almost completely eradicate the role of traditional gatekeeper. In these digital community newsrooms that come from a legacy print background, these editors prove that gatekeeping in terms of content creation has not completely changed, but these journalists are now taking on several different types of gatekeeping roles. This points to a more subtle and less drastic change in gatekeeping practices in those type of newsrooms.

An older theory about gatekeeping is also important to pull back out in this discussion. Gieber (1963) pointed out the idea of "introjective" journalist - those who are 
willing to internalize feelings and values of their audiences in their decision-making. This research shows that engagement editors are more suited toward this newsroom type because of their increased capacity for listening and using audience feedback. Some of their hesitancy in making decisions based solely on audience wants, however, may be in part because of the predominant combative "projective" journalism personality-people in the newsroom who think audience feelings mirror their own - as evidenced by engagement journalists' vocalization of combining "gut" and data in decision-making.

Bourdieu's (1986) theories of capital showed how humans weight different "capital" in decision-making. Though there are many types of capital, in community engagement journalism, economic capital (that is immediately convertible into money) and cultural capital (general knowledge, technical expertise, artistic sense that later can be converted to economic capital) are the most relevant for comparisons. Community engagement editors seem to separate considerations of economic capital (power) and cultural capital in the assessment of what they do and why they do it. Bourdieu (2005) thought that with journalism, economic capital needs took away from cultural capital needs. Engagement editors don't believe this to be the case, though it would be hard to tell if this is truly the case without looking at content to see how much of it made it into the newspaper because of cultural vs. economic capital. Cultural capital acquisition seemed to be the primary concern with business and economic capital concerns coming secondarily, if at all. Two editors, however, were able to vocalize the idea that cultural capital could turn into economic capital, though that relationship was not made directly nor in consideration for the complications of newsroom business practices. Li (2012) 
found that resources management in the newsroom had nothing to do with the newspapers commitment to journalistic cultural capital values. This is certainly the case here, as the line between business and editorial is still drawn very deep in the sand in assessment of value and success for community engagement editors. She also mentioned that there needed to be a better tie between business and editorial for economic viability in the future. It seems there are a few engagement editors trying to understand that tie but they are only able to do so on a surface level. Could this be because of principles-based journalism school education as opposed to that of business values-based education? Nevertheless, it seems that further articulation of what the business side of a newspaper actually does to attain revenue for the business needs would need to be better articulated to the editorial side if they are to make more decisions based on economic capital, though this may detract from cultural capital-based content decisions. The question becomes who has the time for that communication, who will initiate that process, and does the newspaper want business to be influencing editorial decision-making.

These verifications and discrepancies between previous research and this study leave important takeaway points for researchers looking to investigate community engagement journalism in the future. On the level of community engagement journalism, helpful research could be done on how long experimentation has been allowed in a newly professionalized position in the newsroom before accountability and consistency set it. There seems to be an inherent problem with measuring based only on looking on improvement and increase in that at some point there may no longer be increases to report on. At that point, how does a community engagement editor report their success to 
their supervisor? This is important question to answer for the sake of job security in the position. Comparative research on guidance from supervising editors might also be helpful in seeing how feedback is normally given to newsroom employees. It seems that a lack of knowledge about what community engagement editors do within the newsroom makes it hard for supervisors to set benchmarks for the editors to meet. Is this actually the case for supervising editors? In what cases does a lack of benchmarks make editors uncomfortable and in other cases comfortable?

This study had hoped to find that being tapped into the audience made journalists more aware of how their work was business viable. That was not the case with community engagement journalists, which falls into line with traditional journalistic thinking about business and editorial divides within newspapers. Future studies should delve more in-depth for the reasoning behind this. This study raised questions of if a better understanding of marketing, advertising, and circulation would actually help journalists collaborate and feed their efforts into a sustainable business model without trading in their journalistic values. Likewise, future research might want to look into how journalism schools' emphases shade how journalists look at the importance of business considerations in assessing successful journalistic work. This study seemed to show that community engagement journalists can barely vocalize how their journalism benefits a traditional revenue model. What about alternative revenue models? Do journalists who operate outside of an evolving legacy print medium have a better or different understanding of business considerations? 
Finally, more research needs to be done on the audience side of community engagement at newspapers in order to understand if the audience actually finds worth, benefit, or can even tell the difference between engaged and unengaged news they read and interact with. While community engagement editors did assess that crucial idea of cultural capital, they made a dangerous assumption that just because they were contributing to what they thought was better journalism, that the audience would notice that, respect that, and eventually turn monetary resources to that journalism. This may very well be the case, but more research needs to be done with readers where they are asked if they do notice a difference in coverage. If they do, that may signal that community engagement is making positive changes in the news industry. If they don't, that may signal a reassessment of the value of the community engagement position at online newspapers.

There are several practical takeaways this research can contribute to those news organizations wishing to begin or improve the position of community engagement editor. I believe those center around solving the barriers to measurement that current engagement editors vocalized in this study. As previous critics of the public journalism movement noted, this is a hard area to assess the success of given the multifaceted and differentiated nature of the movement itself. In order for better job security for those practicing engagement journalism, there must be steps taken to prove not only the journalistic value and community-building worth of their journalism but, moreover, the economic value. This will lead to better job security for community engagement editors. I believe this starts with more guidance and understanding from leaders and supervisors at 
journalism institutions. Currently, these journalists feel as if they are shooting in the dark with their measurements, unsure of what to be aiming for. With an articulated goal that is more specific than "increase", these journalists will be able operate their measurements in a more succinct and efficient way. Where do these goals come from? Many editors said they felt their bosses barely knew what they did on a day-to-day basis. Perhaps by learning more about what each other's job duties include (such as what upper management's economic goals are) would result in collaborative benchmarks both sides could work to meet. This will lessen feelings of defensiveness or the feeling that engagement editors are doing too many things in too many places and will allow the editor to focus on the most important goals of the whole company. Another solution would be to advocate for more open sharing of metrics-based data between news organizations. This would offer more in-depth comparative data for journalists to make decisions based on. By segmenting market sizes and sharing these numbers, benchmarks could be set that would give those starting from the ground up something to work toward.

Finally, the community engagement editor position is rooted in two combative ideals. On one hand, the position is, by nature, experimental. This denotes a sense of throwing "traditional" ideals of success to the wind. At the same time, the digital foundations of the position mean that editors are keenly aware of the capabilities of measurement. In some respects, it is up to the editor to explain and defend the position against homogenous data-driven decision making for the sake of experimentation. While more decisions could and should be made based on whether engagement work is making or surpassing benchmarks, a good portion of the job should still be devoted to 
experimenting and innovating with what might not seem to make sense based on the numbers. 


\section{CHAPTER EIGHT: CONCLUSION}

Through the use of theoretical framework and qualitative research methods, this study adds to the flow of the dialectic about community engagement, public journalism, journalistic gatekeeping, and Bourdieu's theories of capital. This study also adds to professional practice knowledge of what a community engagement editor does, how they do it, and how they know they are doing it well. This study's findings were closely linked to the original research questions about the day-to-day activities of community engagement journalists, how those journalists assess success and make decisions based off of those assessments, and how these journalists balance journalistic and business values in their work.

As with any scholarly study, there were limitations to this research. First, this study did not seek to define from the ground up what engagement is. This study built on previous public journalism, gatekeeping, and Bourdieu's capital theories to look at the community engagement editor position and how those editors assess success. Secondly, by narrowing down the sample of journalists to those who are community engagement editors, this study excludes many newsrooms that do community engagement but don't have someone specific running those operations - newsrooms like small community newspapers whose very existence is based on community engagement. This study looked at a pretty narrow sample of journalist type-it focused on editors working at digital newsroom with a print component that had a community focus. Thirdly, this study is qualitative in nature and thus cannot and should not be generalized. Instead, as Silverman 
(2010) writes, this study aims for extrapolation instead of generalizability. This research reflects how the findings relate to the world outside of themselves through use of the theoretical frameworks. This study merely attempts to explain how several newsrooms with editors who have adopted engagement techniques have gone about their jobs. Finally, the interviews for this thesis were done without the veil of anonymity on the part of the interviewee. What editors said in response to interview questions could have been shaded by the knowledge that what they spoke of was "on record." The research could have been done differently with names withheld and might provide more candid views of business practices or job security.

Although there are many paths to explore community engagement, this study represents a needed step in scholarly research toward offering practical solutions to questions posed by buzzwords in the journalism field. Community engagement is undeniably one of those terms and deserves to be studied and translated to the rest of the journalism world so that newsrooms can make better-informed decisions in the changing days of the industry ahead. 


\section{APPENDIX A}

\section{Initial Recruitment Email}

Dear

Hello! My name is Kelly Moffitt and I am a journalism Masters student at the University of Missouri, where I'm working on my thesis about how community engagement editors (or those that do similar work but by a different title) assess success in their community engagement efforts. I'm interested in interviewing editors who are involved in community engagement or outreach.

In my background research, I've come upon your name as someone who is a leader in such a capacity. I would love to interview you for my thesis. My study hopes to answer the questions of what an engagement editor is, what of their efforts are considered most successful in newsrooms employing them, how the editors in charge of those efforts measure and assess the success of those efforts, and what the implications of the new role of community engagement editor in journalism are. The title of my research is "Elevating the News: How Engagement Editors Assess Success in their community engagement efforts."

I'm looking to speak with you for around 45-60 minutes about your journalism. Speaking with me is strictly voluntary and you may withdraw at any time if you feel uncomfortable. Your name and position title will be used in research materials.

Please let me know if you would be interested by replying to this email with the preinterview questions I have included at the bottom of this email. I look forward to hearing from you soon and learning about your work.

1. Name:

2. Age:

3. Sex:

4. Job Title:

5. How Long have you worked at your current job:

6. Describe your job in 2-5 sentences:

7. List the three most common ways you engage readers through your work:

Sincerely,

Kelly Moffitt

BJ, University of Missouri, 2012

MA candidate, University of Missouri, 2013

314-607-4488 


\section{APPENDIX B}

\section{Follow-up Recruitment Email}

Hello

I hope you had a pleasant weekend! I just wanted to follow up on an email I sent you last week. I was wondering if you had a chance to consider being interviewed for my Master's thesis about your community engagement work. Your work with seems like it would add a lot to my research. Let me know if you might be interested in talking with me. I can work with whatever time you have to give to interview. Hope to hear from you soon!

Sincerely, Kelly Moffitt 


\section{APPENDIX C}

\section{Interview Guide For Community Engagement Editors}

1. Tell me a little bit about how your position at the newspaper came to be. Why did your boss want you to be doing this work?

2. Describe your position. What are some of your day-to-day activities? What are the goals of your position?

3. Can you describe the difference between your position and a traditional editor in your office?

4. Tell me about the most successful community engagement journalism you have done in the past year. Tell me about what hasn't worked out as well.

5. What does success look like in the engagement journalism you do? How do you know you are doing your job well both in the newsroom and outside the newsroom?

6. What are the different ways you determine if your work has been successful or unsuccessful? Do you have specific metrics or benchmarks you report to someone about? Describe the benchmarks or programs you use to assess your work. Do you have goals you are trying to meet? Does your boss?

7. Can you tell me about types of engagement techniques you've repeated more than once? Why did you do that?

8. How do you balance the assessment of journalistic value and business value of your work? 
9. How does what you do affect the journalists you work with? Do they benefit from the work you do with the community?

10. How do you determine what interactions you have with the community make it into your coverage?

11. What does "good" and "bad" community engagement look like? 


\section{REFERENCES}

Ahva, Laura. (2012). Public journalism and professional reflexivity. Journalism, 14(1), 117.

Bass, A.Z. (1969). Refining the 'gatekeeper' concept: A UN radio case study. Journalism Quarterly, 46, 69-72.

Berger, A. (2000). Media and Communication Research Methods: An Introduction to Qualitative and Quantitative Approaches. Thousand Oaks, California: Sage Publications.

Boczkowski, Pablo J. (2004). Digitizing the News: Innovation in Online Newspapers. Cambridge, Massachusetts: MIT Press.

Bourdieu, Pierre. (1986). The forms of capital. Greenwood, New York.

Bourdieu, Pierre. (2005). The Political Field, the Social Science Field, and the Journalistic Field. In R. Benson \& E. Neveu (Eds.), Bourdieu and the Journalistic Field (pp. 29-47). Malden, MA.: Polity.

Bruns, Axel. (2009). Gatewatching: Collaborative Online News Production. New York, New York: Peter Lang Publishing Inc.

Buttry, Steve. (2011). What does 'community engagement' mean? Blog Retrieved from http://stevebuttry.wordpress.com/2011/06/03/what-does-communityengagement-mean/

Buttry, Steve. (2012). Engagement editors: an emerging, important job in Digital First newsrooms. Blog Retrieved from http://stevebuttry.wordpress.com/2012/03/22/engagement-editors-anemerging-important-job-in-digital-first-newsrooms/

Donohue, G.A., Olien, C.N., \& Tichenor, P.J. (1985). Reporting conflict by pluralism, newspaper type, and ownership. Journalism Quarterly, 62(3), 489-507.

Gandy, P.R. (1982). Beyond agenda setting: Information subsidies and public policy. Norwood, New Jersey: Ablex. 
Gans, Herbert J. (1979). Deciding What's News: A Study of CBS Evening News, NBC Nightly News, Newsweek, and Time. Evanston, Illinois: Northwestern University Press.

Gieber, W. (1963). 'I' am the news. Cincinatti, Ohio: Scripps-Howard Research.

Glaser, B., \& Strauss, A. (1967). The Discovery of Grounded Theory: Strategies for Qualitative Research. Piscataway, New Jersesy: Transaction Publishers, Rutgers.

Kovach, B., \& Rosenstiel, T. (2007). The Elements of Journalism: What Newspeople Should Know and the Public Should Expect. New York, New York: Three Rivers Press.

Lambeth, Edmund B., Meyer, Philip E., \& Thorson, Esther. (1998). Assessing Public Journalism. Columbia, Missouri: University of Missouri Press.

Lessman, Justin R. (2007). The Community Standard: Toward A Model of Community Journalism Decision Making. (Master of Science), Kansas State University, Manhattan, Kansas.

Lewin, Kurt. (1947). Frontiers in group dynamics II. Channels of group life: Social planning and action research. Human Relations, 1, 143-153.

Lewis, Seth C. (2012). The tension between professional control and open participation. Information, Communication, and Society, 15(6), 836-866.

Li, You. (2012). Converting Cultural Capital to Economic Capital in the Journalism Field: Content Management in the Newspaper Business. (Doctor of Philosophy Dissertation), University of Missouri-Columbia, Columbia, Missouri.

Mason, J. (1996). Qualitative Researching. London, UK: Sage Publications.

Mayer, Joy. (2011). A Culture of Audience Engagement in the News Industry. (Master of Arts), University of Missouri-Columbia, Columbia, Missouri.

McNelly, J.T. (1959). Intermediary communicators in the international flow of news. Journalism Quarterly, 36(1), 23-26. 
Merrill, John C., Gade, Peter J., \& Blevens, Frederick R. (2001). Twilight of Press Freedom: The Rise of People's Journalism. Mahwah, New Jersey: Lawrence Erlbaum Associates, Inc.

Napoli, Philip M. (2003). Audience Economics: Media Institutions and the Audience Marketplace. New York, New York: Columbia University Press.

Nip, Joyce. (2006). Exploring the Second Phase of Public Journalism. Journalism Studies, 7(2), 212-236.

Rosen, Jay. (1993). Community Connectedness Passwords for Public Journalism (Vol. 3). St. Petersburg, Florida: The Poynter Institute for Media Studies.

Rosen, Jay. (1996). Getting the Connections Right. United States of America: Twentieth Century Fund.

Rosenberry, Jack. (2005). Few newspapers use online techniques to improve public communication. Newspaper Research Journal, 26(4), 61-73.

Rosenberry, Jack, \& John, Burton St. (2010). Public Journalism 2.0: The Promise and Reality of a Citizen-Engaged Press. New York: Routledge.

Shoemaker, Pamela, \& Vos, Tim P. (2009). Gatekeeping Theory. New York, New York: Routledge.

Silverman, David. (2010). Doing Qualitative Research (Third ed.). London, UK: Sage Publications.

Starkman, David. (2011). Confidence Game: The limited vision of the news gurus. Columbia Journalism Review, November/December 2011.

Vujnovic, Maria, Singer, Jane, Paulussen, Steve, Heinonen, Ari, Quandt, Thorsten, Hermida, Alfred, \& Domingo, David. (2010). Exploring the political-economic factors of participatory journalism. Journalism Practice, 4(3), 285-296.

White, David Manning. (1950). The 'gate keeper': A case study in the selection of news. Journalism Quarterly, 27, 383-390. 